\title{
SILVER ENHANCEMENT OF NANOGOLD AND UNDECAGOLD
}

\author{
James F. Hainfeld \& Frederic R. Furuya \\ Brookhaven National Laboratory \\ Biology Department \\ Upton, New York 11973
}

\begin{abstract}
INTRODUCTION
UNDECAGOLD

NANOGOLD

ADVANTAGES OF USING GOLD CLUSTERS

DISADVANTAGES OF GOLD CLUSTERS

SILVER ENHANCEMENT OF GOLD CLUSTERS

SILVER ENHANCEMENT RATES

APPLICATION TO ELECTRON MICROSCOPY

APPLICATION TO LIGHT AND CONFOCAL MICROSCOPY

APPLICATION TO BLOTS

HEATING GOLD CLUSTERS

APPLICATION TO GELS
\end{abstract}

\section{INTRODUCTION}

Most previous work with immunogold silver staining has been done with colloidal gold particles. More recently, large gold compounds ("clusters") having a definite number of gold atoms and defined organic shell, have been used, frequently with improved results (Vandré and Burry, 1992). These gold clusters, large compared to simple compounds, are, however, at the small end of the colloidal gold scale in size; undecagold is $0.8 \mathrm{~nm}$ and Nanogold is $1.4 \mathrm{~nm}$. They may be used in practically all applications where colloidal gold is used (light and electron microscopy, dot blots, etc.) and in some unique applications, where at least the larger colloidal golds don't work, such as running gold labeled proteins on gels (which are later detected by silver enhancement). The main differences between gold clusters and colloidal golds are the small size of the clusters and their covalent attachment to antibodies or other molecules.

\section{UNDECAGOLD}

The gold core of undecagold, which contains 11 gold atoms, is $0.8 \mathrm{~nm}$ in diameter. The structure of this cluster has been solved by $x$-ray diffraction of crystals (McPartlin et al., 1969), and is shown in Figs. 1 and 2. Including the organic shell, the overall diameter is $2.0 \mathrm{~nm}$. One or more of the organic moieties around the periphery of this cluster may be derivatized to a functional group, 
such as an amine (Bartlett, et al., 1978), a maleimide (reacts with thiols, Yang, Reardon, and Frey, 1984, Safer et al., 1986), or N-hydroxysuccinimide ester (reacts with amines, Reardon and Frey, 1984), so that the cluster can be covalently attached to IgG, Fab, or other molecules, including lipids, peptides, proteins, carbohydrates, lectins, and nucleic acids. The attachment is stable (covalent) and specific (coupling to a specific amino acid or site). For example, the undecagold may be coupled to the hinge sulfhydryl of an Fab' fragment (Fig. 3 , Hainfeld, 1987). The product may be isolated by gel filtration chromatography to remove any unbound gold cluster, and the reaction is virtually quantitative, that is, almost all Fab' molecules are labeled with a gold cluster (Fig. 4). The undecagold cluster is small enough (MW $=5,000)$ that it hardly affects the properties of the antibodies, as seen by their identical retention time by gel filtration HPLC and identical or only slightly altered $R_{f}$ on polyacrylamide electrophoresis gels.

Although the undecagold cluster has many interesting applications, such as high resolution single molecule electron microscopy (Hainfeld, et al., 1991, Hainfeld, 1992, Milligan, Whittaker, and Safer, 1990), it also has a few disadvantages: it is so small that it is difficult to see in TEM (although it is seen quite well in the high resolution scanning transmission electron microscope (STEM)); it is even more difficult to visualize in the EM when it is over $\sim 20 \mathrm{~nm}$ of protein (without silver enhancement); it is sensitive to beam damage by the electron beam and becomes less visible with higher doses (Wall et al., 1982); and it does not develop with silver robustly. However, upon studying its silver enhancement properties further for this report, we find that it should be quite useful and unique for many applications.

\section{NANOGOLD}

Because of the limitations of undecagold, a larger gold cluster with a 1.4 nm gold core was developed (Hainfeld and Furuya, 1992) (Fig. 5). This too has an organic shell, giving an overall diameter of $2.7 \mathrm{~nm}$. Although crude preparations may contain small amounts of a smaller cluster, it is, on the whole, very uniform, and a major fraction can be purified that is extremely uniform and even forms microcrystals (Fig. 6). This cluster, termed $\mathrm{Au}_{1.4 \mathrm{~nm}}$, or "Nanogold", turned out to have very interesting properties. It can be covalently attached to target molecules in a similar way to undecagold (Figs. 7,8). Nanogold is much more visible than undecagold in the EM, does not damage in the beam, and develops well with silver (Hainfeld and Furuya, 1992).

\section{ADVANTAGES OF USING GOLD CLUSTERS}

There are several benefits gained by using undecagold or Nanogold over traditional colloidal gold: 1) Due to their small size, penetration into, e.g., permeabilized tissue, is significantly better (Burry, Vandré, and Hayes, 1992), up to 40 times that of colloidal gold probes (even when compared to $1 \mathrm{~nm}$ colloidal gold probes), and they can diffuse up to $20 \mu \mathrm{m}$. Fab' antibody probes may be 


\section{DISCLAIMER}

Portions of this document may be illegible in electronic image products. Images are produced from the best available original document. 
routinely made, whereas IgG probes are used with most colloidal gold probes. The use of the Fab' fragment (MW $=50,000)$ already reduces the size of the probe by a factor of $\sim 3$ from those made with IgG (MW=150,000). 2) It has been commonly found that smaller gold particles lead to a greater staining density than larger gold particle probes (Hayat, 1989). Use of the ultrasmall gold clusters (Nanogold-Fab') has also been shown to effect more quantitative antigen labeling (Vandré and Burry, 1992). 3) The attachment of gold clusters is covalent and stable, whereas colloidal probes undergo dissociation (Horisberger and Clerc, 1985). Dissociation leads to free antibody which competes for target sites and reduces signal (Kramarcy and Sealock, 1990). 4) Gold cluster labeled antibodies are not aggregated as colloidal gold preparations are wont to do. In colloidal gold immunoconjugates, the IgG molecules are adsorbed to the gold particles. Since the gold is "sticky", it tends to aggregate. With the gold cluster approach, the immunoglobulin is coupled only at a specific site, and no aggregation occurs. The gold is not "sticky" and does not attach without chemical activation. In fact, the conjugates are routinely chromatographed using gel filtration, and no aggregates are observed, even upon storage. 5) There is typically 1 antibody per gold cluster, whereas with colloidal gold there may be 0.4-25 proteins per gold particle (Horisberger and Clerc, 1985). 6) The size of the gold clusters are very precise since these are compounds; larger colloidal gold particles can be very regular, but smaller ones $(<3 \mathrm{~nm})$ are heterogeneous. " $1 \mathrm{~nm}$ " colloidal gold can vary from 1-3 nm (Hainfeld, 1990). 7) For immunoconjugates, the gold clusters are usually covalently attached to the hinge sulfhydryl of Fab' or IgG. This is away from the hypervariable binding region of the antibody, so antibody activity is generally completely retained. With colloidal gold, antibodies may attach such that they are no longer active. 8) The small size of the gold clusters improves resolution over larger colloidal gold probes. 9) Gold clusters are available as reagents and can be covalently reacted with antibodies and many other molecules to make a variety of specific molecular probes that are not possible with the colloidal gold approach. For example, the gold clusters may be attached to IgG through their carbohydrate moiety, to nucleic acid bases, to hormones, and potentially to single chain antibodies.

Because of these advantages, generally a much higher density of gold labeling is observed than with colloidal gold (Vandré and Burry, 1992), and many unique experiments may be designed that are not possible using colloidal gold.

\section{DISADVANTAGES OF GOLD CLUSTERS}

For particular applications, use of colloidal gold probes may be preferable to gold clusters. The disadvantages of the gold clusters are: 1) They are very small, $0.8 \mathrm{~nm}$ or $1.4 \mathrm{~nm}$. For routine EM work at low magnification, $10-20 \mathrm{~nm}$ gold does not require silver enhancement and may be more convenient. 2) For post embedding work, where diffusion of label is not significant (antibodies do not penetrate the plastic), there may be less of an advantage gained by using cluster conjugates compared with colloidal gold conjugates. 3) Although the clusters 
are regular, after silver enhancement to $5-20 \mathrm{~nm}$, their size is then more irregular than colloidal gold of that size. It is therefore more difficult to use them in double labeling schemes. 4) The undecagold develops to give less signal than Nanogold; so even though undecagold is smaller and might seem to be the preferable choice under the criteria under 'advantages' above, Nanogold may give more satisfactory silver enhanced results. 5) For "do-it-all-yourself" investigators, the gold clusters are much more difficult to make than colloidal gold, involving multistep organic and inorganic syntheses.

\section{SILVER ENHANCEMENT OF GOLD CLUSTERS}

For high resolution EM applications, where the small gold clusters are visible directly, silver enhancement is not necessary and would detract from those results. These applications include study of individual molecules either unstained (Hainfeld, 1992) or in a low density stain (e.g., vanadate, where the gold is still visible, Hainfeld et al., 1993), in ice embedded (frozen hydrated) samples (Boisset et al., 1992, Wilkens and Capaldi, 1992), and in crystalline or helical arrays where image processing may be applied (Milligan, Whittaker, and Safer, 1990). Recent work with thin sections by Stierhof, et al. (1992), using dark field electron microscopy, demonstrated visibility of $1 \mathrm{~nm}$ gold (colloid) directly and should be applicable to gold cluster labeling.

For most other applications, silver enhancement is required. These applications include standard immunocytochemistry using the EM or light (or confocal) microscope, and gold staining of gels and blots. Upon the introduction of Nanogold, its excellent response to silver enhancement was documented (Hainfeld and Furuya, 1992). It was used for LM identification of cell types, and on immuno-dot blots, where it showed exceptional sensitivity, down to $0.1 \mathrm{pg}$, or $10^{-18}$ moles, thus making it more sensitive than most radioactive, fluorescent, and enzymatic probes.

Some previous LM and EM work was also reported by Burry, Vandré, and Hayes (1992), where they compared Nanogold silver enhancement to that of 1 $\mathrm{nm}$ colloidal gold. They found that upon enhancement, Nanogold gave more uniform particle sizes and a better correlation between enhancement time and particle density. After $6 \mathrm{~min}$ of development, the particles had an average size of $20 \mathrm{~nm}$; after $15 \mathrm{~min}$, the sections were optimal for light microscopy localization. These results were with N-propyl gallate (NPG) enhancer, and differences may be found with alternative silver enhancer preparations. They also observed a shrinking of silver particles upon post treatment with $\mathrm{OsO}_{4}$.

In a study of immuno-localization of proteins associated with the mitotic spindle, Vandré and Burry (1992) found that Nanogold-Fab' was superior to other colloidal gold probes, including a $1 \mathrm{~nm}$ one. They compared penetration, label uniformity and labeling density using various gold probes, followed by silver enhancement. The tissue in this study was fixed with glutaraldehyde $(0.7 \%)$, permeablized with saponin $(0.1 \%)$, reacted with primary $\left(60 \mathrm{~min}, 37^{\circ}\right)$ then secondary antibodies $\left(60 \mathrm{~min}, 37^{\circ}\right)$, postfixed with glutaraldehyde $(1.6 \%)$, silver enhanced (with NPG, 5 min for EM, 8-10 min for LM), osmicated (30 min, 
$0.1 \%)$, then embedded in Epon and sectioned. A tertiary fluorescein conjugated antibody test indicated that an equivalent amount of secondary antibody had reached the microtubules from the Nanogold and 1nm colloidal probe, but the silver staining was much poorer with the colloidal gold. This implied that free antibody was present in the colloidal gold preparation and degraded its gold staining performance. Nanogold localizations correlated exactly with conventional indirect immunofluorescence, and permitted ultrastructural determination at high resolution. Use of 10-20 nm colloidal gold preparations failed to penetrate adequately into the structures of interest in this study and gave unsatisfactory results. Light microscopy of silver enhanced samples also showed better staining with Nanogold compared to the $1 \mathrm{~nm}$ colloidal gold. For localization of MPM-2 antibody, only the Nanogold conjugates demonstrated specific localization to the centrosome and kinetochores by EM, confirming immunofluorescence localization studies. This study demonstrated the ability of Nanogold probes to penetrate into dense, structurally complex cytoskeletal organelles, such as the centrosome and the midbody.

Another study with $1 \mathrm{~nm}$ colloidal gold immunoconjugates demonstrated significant microaggregation of the gold and antibody, thus making the effective size of the "1 nm" colloidal gold probe much larger (Hainfeld, 1990). This would also explain the significantly lower gold/silver staining compared to Nanogold, where the Fab'-Au $1.4 \mathrm{~nm}$ conjugates are monomolecular, chromatographically purified, and not aggregated at all.

This chapter attempts to further quantitate the silver enhancement properties of undecagold and Nanogold, compare these results with silver enhancement of colloidal gold, and show several applications.

\section{SILVER ENHANCEMENT RATES}

Previously, development rates of colloidal golds have been studied (Gu et. al., 1993), as well as Nanogold compared with $1 \mathrm{~nm}$ colloidal gold (Burry, Vandré, and Hayes, 1992). Here we expand the study to include undecagold, Nanogold, 1, 3 and 15nm colloidal gold. Colloidal golds were first stabilized with bovine serum albumin (BSA) to prevent aggregation upon addition of the enhancer.

Traditionally, EM samples at various times of development have been used to study and document the rate of silver growth. Here we have also used ultraviolet-visible (uv-vis) spectroscopy to quantify initial silver growth. The experiment was to incubate a gold solution with silver developer (LI Silver, Nanoprobes) in a disposable cuvette in a diode array spectrophotometer (Hewlett Packard 8452A), and record spectra every minute. At first, everything is in solution and small silver particle growth can be monitored. Later, large silver particles contribute heavily to light scattering, they eventually fall out of solution, and extensive amounts of silver coats the walls of the cuvette forming a silver mirror. Although there are shortcomings of this method, it appears illuminating, particularly for early development times. 
The first sample is the developer alone. Silver enhancers are known to autonucleate typically after about $30 \mathrm{~min}$ and produce some silver particle background. The spectral changes over time are shown in Fig. 9. These changes can be plotted versus time if a particular wavelength is followed. The wavelength selected should be one that exhibits the most change. In this case, the range of 430 to $450 \mathrm{~nm}$ was averaged (to reduce noise) since a peak at $\sim 440$ $\mathrm{nm}$ appears strongly over time. Much of the general light scattering and deposition on the walls results in less transmittance, which can be roughly monitored by the absorbance at $\sim 800 \mathrm{~nm}$ (an average of 800 to 820 was used). The difference of the 440 absorbance minus this background at $800 \mathrm{~nm}$ should better represent the solution behavior. These signals are plotted in Fig 10 for the silver developer.

Similarly, other gold solutions may be studied. Nanogold development is shown in Figs. 11 and 12. A final peak at $\sim 440 \mathrm{~nm}$ develops similar to the silver developer alone. However, development is $\sim 10,000$ times faster, although it is difficult to estimate this factor from these measurements. Also, the absorbance at $810 \mathrm{~nm}$ rapidly rises after $\sim 2 \mathrm{~min}$ (Fig. 12), indicating significant deposition of silver on the walls of the cuvette and light scattering. For comparison, development of a $\sim 10$ fold more dilute Nanogold solution is shown in Fig. 13. Since the gold still produces a strong signal, it raises the question as to what level of gold could be ultimately detected by this means (uv-vis spectroscopy with silver enhancement). Therefore, a very dilute Nanogold solution was measured that gave a significant reading over the background silver enhancer alone. This is shown in Figs. 14 and 15. The absorbance (at $440 \mathrm{~nm}$ ) vs. time for this dilute gold solution with silver enhancer compared with the silver enhancer alone is plotted in Fig. 16. A significant difference can be detected in 5-10 min.

Assuming a $50 \mu \mathrm{l}$ cuvette cell, this would give a detection of $\sim 10^{-13}$ moles by this method.

Undecagold silver enhancement was subjected to the same uv-vis spectral analysis. This is shown in Figs. 17 and 18. The spectra show a very sharp peak appearing at $370 \mathrm{~nm}$. Usually sharp peaks are indicative of a tight size distribution or perhaps a new gold-silver alloy cluster that is well defined. Further work is needed to characterize this new product. It is clear that the endpoint (after $15 \mathrm{~min}$ ) is quite different from that of the Nanogold or silver enhancer alone (they have peaks at $440 \mathrm{~nm}$ ). A second difference between the undecagold and Nanogold is the slow and somewhat delayed development of the undecagold. Undecagold starts out with almost a zero rate which then picks up after a few minutes (Fig. 18). Also, the concentration of undecagold was about 5 times higher than that of the Nanogold shown in Figs. 11 and 12, but it gave less overall development. Silver enhancement of undecagold is therefore slower and less robust than that of Nanogold. That is not to say, however, that use of undecagold should not be considered further. It is a smaller probe, and the overall performance with silver enhancement, as shown later, can be quite useful in most applications. For comparison, the results for Nanogold and undecagold discussed thus far are plotted on the same scale in Fig. 19. 
For comparison, $3 \mathrm{~nm}$ colloidal gold was treated in the same fashion (Figs. 20 and 21). The $3 \mathrm{~nm}$ gold shows the usual appearance of a peak at $440 \mathrm{~nm}$. Compared to the Nanogold, development at approximately the same gold concentration (Fig. 13), there is relatively little coating of the walls with silver or heavy light scattering (as judged by $810 \mathrm{~nm}$ absorption) for the $3 \mathrm{~nm}$ gold, but an extensive amount with the Nanogold. More silver product is produced by the Nanogold, so it appears more efficient at silver development.

$15 \mathrm{~nm}$ colloidal gold development is shown in Figs. 22 and 23. The usual $530 \mathrm{~nm}$ peak for this size colloidal gold is seen in its spectrum at zero time (the lowest spectrum in Fig. 22). Development is accompanied by a shift of the 530 $\mathrm{nm}$ peak to $500 \mathrm{~nm}$, and an appearance of the usual $440 \mathrm{~nm}$ peak. Similar to the 3 $\mathrm{nm}$ colloidal gold, there is little change in the 810 absorption. The solution remains clear but colored over this time, and is free of any noticeable gross silver deposition. Much more silver product is observed than with the Nanogold of a similar concentration (Fig. 15), where an O.D. value of only 0.07 is reached after $30 \mathrm{~min}$, whereas the $15 \mathrm{~nm}$ gold gave 0.9 O.D. after $10 \mathrm{~min}$. There are, however, approximately 1,000 more gold atoms per $15 \mathrm{~nm}$ particle than per Nanogold, and this affects the results. Development of 40 times more dilute $15 \mathrm{~nm}$ colloidal gold solution is shown in Figs. 24 and 25. A slightly different behavior is observed than for the more concentrated sample. The peak at $530 \mathrm{~nm}$ shifts to 500 then 480 $\mathrm{nm}$, but instead of a peak at $440 \mathrm{~nm}$, one at 570 appears. Development is also accompanied by a larger proportional shift in the $810 \mathrm{~nm}$ absorbance. On a molar basis, $15 \mathrm{~nm}$ colloidal gold is more detectable than Nanogold under these conditions.

\section{APPLICATION TO ELECTRON MICROSCOPY}

As far as we know, there has not been any use of undecagold probes with silver enhancement previously reported. As shown above, they do develop, albeit slower than other gold particles. The advantage of their smaller size may compensate for their slower development. A TEM micrograph of silver enhanced undecagold is shown in Fig. 26. There is some diversity of sizes, but many particles are $\sim 10 \mathrm{~nm}$, a useful range for ultrastructural EM studies. The use of undecagold probes with silver enhancement for such uses should be pursued further.

Nanogold develops more rapidly than undecagold, as shown above. A typical TEM micrograph of silver enhanced Nanogold is shown in Fig. 27.

Gold cluster immunoprobes are the smallest commercially available (they may be obtained from Nanoprobes, Inc., Stony Brook, N.Y., or such distributors as U.S.: E.F. Fullam, Polysciences; Japan: Cosmo Bio Co., Funokoshi, Ltd., Wako Chemicals; Germany: Biotrend, Ltd.). Use of Fab'-Nanogold ( $\left.\mathrm{Au}_{1.4 \mathrm{~nm}}\right)$ is considerably smaller than IgG-1nm colloidal gold because the Fab' fragment is $\sim 1 / 3$ the size of the IgG; additionally, there is no aggregation. Although Fabcolloidal gold probes have been made (Baschong and Wrigley, 1990), they are stabilized by adsorbing BSA typically, which is larger $(68 \mathrm{kD})$ than the Fab fragment $(50 \mathrm{kD})$, thus increasing the overall probe size. The most striking 
improvements in immunolabeling with gold cluster probes over colloidal gold are often observed in pre-embedding localization where penetration of the probe is an important factor. The small probes penetrate and more quantitatively label antigens. Subsequent silver enhancement leads to a strong signal and improved localizations.

An example of the excellent immunostaining obtainable using NanogoldFab' followed by silver enhancement, done by Dr. Susan J.-H. Tao-Cheng, is shown in Fig. 28, where synaptophysin was localized in PC12 cell neurites. Other examples of pre-embedding use are found in an article by Vandré and Burry (1992) where they found dramatic improvement in immunolabeling at the EM level using Nanogold probes compared to $1 \mathrm{~nm}$ and other sized colloidal gold probes.

Post-embedding immunostaining using antibodies coupled to Nanogold (followed by silver enhancement) has also given improved results. A beautiful example of this, provided by Dr. Sarah Bacon, is shown in Fig. 29, where GABAcontaining terminals from rat spinal cord were clearly identified.

\section{APPLICATION TO LIGHT AND CONFOCAL MICROSCOPY}

The greatly improved penetration of Nanogold-Fab probes over colloidal gold probes can also provide dramatic results for light and confocal microscopy. One example of this is the staining of a nuclear oncogene protein by Dr. Yair Gazitt. A primary monoclonal antibody was used, followed by goat-anti-mouseFab'-Nanogold, then silver enhancement with LI Silver. This is shown in Fig. 30. Intense staining was observed in the nucleus where expected, confirming results with fluorescently labeled secondary antibodies. An interesting aspect of this study was that a wide variety of commercial colloidal gold immunoprobes with different sized golds were tested and all failed to access the nucleus and stain the antigen.

Another excellent result was obtained by Drs. Dale Vandré and Richard Burry (1992). They immunostained cells during mitosis with anti-tubulin antibodies and probed with Nanogold-Fab', followed by silver enhancement. Intense and specific staining of the spindle microtubules was observed (Fig. 31 A). A parallel experiment using $1 \mathrm{~nm}$ colloidal gold-IgG probe showed only weak staining (Fig. $31 \mathrm{~B}$ ).

These results indicate that frequently better results can be obtained in immunocytochemistry for light microscopy using the small Nanogold probes and silver enhancement than with colloidal gold probes, especially when tissue or cell penetration is a factor, e.g., when probing for internal cellular structures.

\section{APPLICATION TO BLOTS}

Immuno dot blots using colloidal gold labeled secondary probes have been previously described (Moeremans et al., 1984). Silver enhancement of these dot blots gave excellent sensitivity, and were deemed to be more sensitive than radioactive or fluorescent probes (Moeremans et al., 1984, Hsu, 1984, Holgate et 
al., 1983, Wu, Mahony, and Chernesky, 1990). The gold clusters (undecagold and Nanogold) may also be used in this application. The question is, are they more sensitive than colloidal gold or are there other advantages/disadvantages to their use? For blots, development is carried out for longer times (20 to $60 \mathrm{~min}$ ) than for EM or LM to produce a maximal amplification and size of the silver particles. Their size is then generally beyond that useful for EM. Also, the development is near the longest possible without incurring excessive background (due to developer self nucleation), in order to achieve maximal sensitivity and visibility. Development can be extended with fresh enhancer solution every $20-30 \mathrm{~min}$ (after an intervening water wash), since the self-nucleation process is dependent upon the time the enhancer sits once mixed. At some point, however, no further improvement in signal-to-noise ratio is seen (usually at 30-60 min), even after applying fresh developer solutions. The silver grains presumably slow in growth or their percentage change in radius decreases.

In order to investigate the sensitivities achieved on blots, several experiments were done. One was to spot known concentrations of gold solutions (without antibody) directly onto nitrocellulose paper. After drying, these were developed with silver enhancer. Typical results showing undecagold and Nanogold are shown in Fig. 32. This showed a sensitivity (minimal amount detected by eye) of $10^{-19}$ moles for Nanogold and $10^{-15}$ moles for undecagold. Similar blots were done for 1,3, and $15 \mathrm{~nm}$ colloidal gold, and the sensitivities for all are summarized in Table 1:

Table 1. Sensitivity (minimal amount detected by eye) on blots of gold solutions only, spotted on nitrocellulose, dried, then silver enhanced for $30 \mathrm{~min}$.

Experimental error, determined from several runs, is in the order of a factor of 510.

\begin{tabular}{|l|c|}
\hline \multicolumn{1}{|c|}{ Gold } & Sensitivity (moles) \\
\hline Undecagold & $10^{-15}$ \\
\hline Nanogold & $10^{-19}$ \\
\hline $1 \mathrm{~nm}$ colloidal & $10^{-15}$ \\
\hline $3 \mathrm{~nm}$ colloidal & $10^{-16}$ \\
\hline $15 \mathrm{~nm}$ colloidal & $10^{-18}$ \\
\hline
\end{tabular}

These results show that Nanogold reaches a silver enhanced endpoint that is slightly greater than $15 \mathrm{~nm}$ colloidal gold on a molar basis. This is different from the solution development results followed by uv-vis spectroscopy reported above, where the $15 \mathrm{~nm}$ gave a better signal for dilute solutions. Undecagold seems comparable to $1 \mathrm{~nm}$ colloidal gold.

Gold clusters have an organic shell and are stable in salt solutions; gold colloids made by the usual means have a thin ionic shell of $\mathrm{AuCl}_{2}^{-}$and $\mathrm{H}^{+}$ (Weiser, 1933), but the sols are unstable to the addition of salts or many other molecules which cause the particles to aggregate. Colloidal gold is stabilized by the adsorption of immunoglobulins, BSA, or other polymers, such as Carbowax 
(a type of polyethylene glycol, PEG). These adsorbents form a coating around the gold. A question is whether these coatings affects the development by silver enhancers. To answer this, the above blot experiments were repeated with the golds conjugated to antibodies (Nanogold and undecagold), and antibodies followed by the usual BSA stabilization for the colloidal golds. Since the golds absorb in the visible range, the amount of gold may still be measured. Results from these tests gave the same resultant sensitivities as gold without antibodies listed in Table 1. The protein attachment does not therefore appear to interfere with silver enhancement.

Another level of testing is to put a target molecule on the nitrocellulose, e.g., mouse IgG, block the rest of the paper with the usual BSA blocking solution, then incubate with goat anti-mouse antibody attached to the various golds studied. Sensitivity of detection is then measured. This corresponds to the usual immunodot blot procedure and therefore compares the conjugates and should indicate the best one for this application. Examples are shown in Fig. 33 for Nanogold-IgG and undecagold-IgG. A compilation of the sensitivities for the various golds is given in Table 2:

Table 2. Sensitivity (minimal amount detected by eye) on immunodot blots of gold immunoprobes (goat anti-mouse) to a mouse IgG target (the antigen), after silver enhancement for $30 \mathrm{~min}$. More sensitive results have been obtained $\left(10^{-13}\right.$ $\mathrm{g}$, see fig 34), but these are reported since the same antibody and antigen preparations were used for all the golds, giving a better comparison.

\begin{tabular}{|l|c|c|}
\hline \multicolumn{1}{|c|}{ Gold Immunoprobe } & Sensitivity (g target) & Sensitivity (moles target) \\
\hline Undecagold & $10^{-8}$ & $10^{-13}$ \\
\hline Nanogold & $10^{-11}$ & $10^{-16}$ \\
\hline $1 \mathrm{~nm}$ colloidal & $10^{-9}$ & $10^{-14}$ \\
\hline $3 \mathrm{~nm}$ colloidal & $10^{-7}$ & $10^{-12}$ \\
\hline $15 \mathrm{~nm}$ colloidal & $10^{-11}$ & $10^{-16}$ \\
\hline
\end{tabular}

These results indicate that Nanogold and $15 \mathrm{~nm}$ colloidal gold immunoconjugates give about the same sensitivity, and that undecagold conjugates are $\sim 1,000$ times less sensitive in this application, and perform slightly worse than $1 \mathrm{~nm}$ colloidal gold conjugates.

Immunoblots are dependent on the quality of the antigen and antibody used, as well as the alterations that may occur upon conjugation to the gold. The above immunodot blots used the same antibody and antigen material for comparison. However, we frequently observe more sensitive detection using the Nanogold conjugates. An example of this is shown in Fig. 34 where $0.1 \mathrm{pg}$ mouse IgG target was detected, corresponding to $6.7 \times 10^{-19}$ moles of target antigen. This is similar to the $5.5 \times 10^{-18}$ moles (of target DNA) detected using chemiluminescence (Pollard-Knight et al., 1990). However, the chemiluminescent experiment required a $12 \mathrm{hr}$ exposure of film and subsequent development, whereas the gold detection produces a permanent record directly 
in $\sim 30 \mathrm{~min}$. It appears that gold detection on blots may rival the other most sensitive detection schemes thus far developed.

\section{HEATING GOLD CLUSTERS}

One ancillary point is whether the gold clusters are sensitive to heating, since many procedures require a heating step, for example, curing of Epon or other embedding resins at $60^{\circ}$, or boiling proteins in SDS before electrophoresis. Yang, Reardon, and Frey (1984) described "marked, progressive changes in the visible absorption spectrum" detectable within a few minutes when heating undecagold in the presence of air. They reported most decomposition did not occur under anaerobic conditions, or in the presence of borohydride.

We have therefore now measured the sensitivity of the gold clusters to heating at various temperatures for various times in various solvents. They are, on the whole, very resistant to heating. Integrity was assessed by measuring the change of absorbance at $420 \mathrm{~nm}$. At room temperature or $37^{\circ}$ there was no significant loss $(<10 \%)$ for undecagold or Nanogold after 4 hours, either in PBS or $20 \mathrm{mM}$ phosphate, $\mathrm{pH} 7.4,0.5 \mathrm{M} \mathrm{NaCl}$. At $60^{\circ}$ the undecagold showed no change after 4 hours, but the Nanogold showed about a $20 \%$ loss. At $100^{\circ} \mathrm{C}$, the undecagold was stable for at least 4 hours, and the Nanogold showed $42 \%$ loss during this period (Fig. 35). Behavior was similar in the buffers mentioned. Interestingly, heating to $100^{\circ}$ in $1.3 \%$ SDS for $5 \mathrm{~min}$ of either undecagold or Nanogold caused no loss, so the SDS may stabilize the structures. The results of Yang, Reardon, and Frey (1984) were confirmed by first bubbling air into the undecagold solution for 1 hour. After that, heating for $5 \mathrm{~min}$ at $100^{\circ}$ caused a $23 \%$ loss of cluster.

Blots of clusters that had been heat treated to $100^{\circ}$ (i.e., the gold was applied to a nitrocellulose paper, dried, then silver enhanced) showed approximately the same sensitivity as unheated gold. Slight losses in detectability, comparable to the losses detected by UV ( $420 \mathrm{~nm}$ measurements, Fig. 35), were observed in the blots.

It appears from this study that undecagold may be used in degassed buffers at $100^{\circ}$ over long periods, and that Nanogold may be also be heated without terribly significant losses even at $100^{\circ}$ for 1 hour.

\section{APPLICATION TO GELS}

Colloidal gold immunoconjugates have previously been used to detect bands on blot transfers of gels (Moeremans et al., 1984). Most stabilized colloidal gold is negatively charged, but it can also be positively charged by coating with polylysine (Skutelsky and Roth, 1986). These charged gold particles have now been tried as post-run gel stains which presumably work by differential affinity for proteins or nucleic acids vs. affinity for the gel material; sometimes more gold binds to the gel matrix leading to a negative staining of bands. Initial transfer of the gel band to a blot material (e.g., nitrocellulose) is frequently required since 
diffusion of gold colloids into the gel matrix is poor, whereas staining of a blot is closer to a surface binding situation.

Gold clusters may be used in the same way: immunoconjugates may be used, or positive, negative, and uncharged gold clusters may be synthesized to exploit other staining strategies. In addition, the small size of the gold clusters permits easy diffusion into gels and avoids the necessity of first making blot transfers.

Another possibility is to actually electrophorese the clusters on a gel. Undecagold monomers and synthetic undecagold dimers were separated by SDS polyacrylamide gel electrophoresis (PAGE) by Yang, Reardon, and Frey (1984). Furthermore, it should be possible to run gold cluster-labeled proteins on gels. Since gold clusters are relatively small compared to most proteins, and since they are covalently bound, they should run with the protein during PAGE. This was reported for an undecagold labeled ribosome subunit by Weinstein et al. (1989). The $5 \mathrm{kD}$ weight of the cluster appeared to retard the migration by that amount on the gel, so that labeled and unlabeled proteins could be distinguished. Another example was provided by Boeckh and Wittmann (1991), where another ribosomal protein was labeled and run on PAGE, and the labeled protein was retarded by the weight of the cluster. Staining was by Coomassie and conventional gel silver staining.

Further work in our laboratories has shown that Nanogold also may be used directly in gels; some samples however indicated no detectable retardation corresponding to the weight of the cluster. Perhaps it is small enough or embedded well enough to only marginally alter the protein migration. A further study showed that if the sample (including protein and SDS) was not heated before running, some gold labeled protein bands were retarded. However, under these conditions (no heating), some native proteins also run anomalously. If, however, they were boiled for $5 \mathrm{~min}$ before running (with SDS), native proteins ran as expected, and the Nanogold labeled bands then also ran identically to unlabeled protein (Fig. 36).

An interesting finding was that silver enhancement of gold cluster-labeled proteins run on gels yielded intense bands after only a few minutes of development, compared to the usual 1-4 hours required for regular gel staining. This intense staining was with a stoichiometry of one gold cluster per protein molecule. Unlabeled protein bands do not develop with even extended silver enhancement times. Use of this property permits one to selectively stain and determine labeled subunits, for example. A parallel gel using Coomassie Blue would indicate total protein distribution (e.g., Fig. 36).

There is one restriction to using gold clusters on gels: The gold clusters are sensitive to reducing agents, such as $\beta$-mercaptoethanol (BME) or dithiothreitol (DTT); they decompose over a period of time in these reagents. Therefore, these gold clusters are not very useful for reducing gels, but may be used successfully with native or (non-reducing) SDS gels.

The specific staining of Nanogold labeled subunits on gels was used by Wilkens and Capaldi (1992) to identify the subunit labeled in a multicomponent system, F1 ATPase. They also did immunological identification of the bands to 
The common silver stain specifically designed for staining protein or nucleic acid gels was found to more effectively (densely) stain gold cluster labeled bands; the normal staining procedure and approximate time may be used. Use of this stain shows the gold labeled bands first, then the non-labeled bands develop. This is in contrast to the usual silver enhancers for gold which only develop the gold labeled bands.

\section{SUMMARY}

A recent advance in immunogold technology has been the use of molecular gold instead of colloidal gold. A number of advantages are realized by this approach, such as stable covalent, site-specific attachment, small probe size and absence of aggregates for improved penetration. Silver enhancement has led to improved and unique results for electron and light microscopy, as well as their use with blots and gels.

\section{ACKNOWLEDGMENTS}

The authors would like to thank Kyra Carbone, Inan Feng, and Beth Lin for excellent technical assistance; Martha Simon and Frank Kito for operation of the STEM, and Joseph Wall for fruitful discussions. We also thank Drs. Sarah Bacon, Susan J.-H. Tao-Cheng, Dale Vandré, Richard Burry, and Yair Gazitt for contributing beautiful immunocytochemical micrographs. This work was supported by the Office of Health and Energy Research of the U.S. Department of Energy.

\section{REFERENCES}

Bartlett, P.A., Bauer B., and Singer, S.J. 1978. Synthesis of water-soluble undecagold cluster compounds of potential importance in electron microscopic and other studies of biological systems. I. Am. Chem. Soc. 100: 5085 .

Baschong, W. and Wrigley, N.G. 1990. Small colloidal gold conjugated to Fab fragments or to immunoglobulin $\mathrm{G}$ as high-resolution labels for electron microscopy: a technical overview. L. Electron. Microsc. Tech. 14: 313.

Boeckh, T. and Wittmann, H.-G. 1991. Synthesis of a radioactive labeled undecagold cluster for application in X-ray structure analysis of ribosomes. Biochim. Biophys. Acta 1075: 50 .

Boisset, N., Pochon, F. Chwetzoff, S., Barray, M., Delain, E., and Lamy, J. 1992. Electron microscopy of $\alpha_{2}$-macroglobulin with a thiol ester bound ligand. L Struct. Biol. 108: 221. 
Burry, R.W., Vandré, D.D., and Hayes, D.M. 1992. Silver enhancement of gold antibody probes in pre-embedding electron microscopic immunocytochemistry. L. Histochem. Cytochem. 40: 1849.

Gu, J. D'Andrea, M., Yu, C.-Z., and McGrath, L.B. 1993. Quantitative evaluation of indirect immunogold-silver electron microscopy. L. Histotech. 16: 19.

Hainfeld, J. F. 1987. A small gold-conjugated antibody label: Improved resolution for electron microscopy. Science 236: 450.

Hainfeld, J.F. 1990. STEM analysis of Janssen Auroprobe One. In Proc. XIIth Int. Cong. Elec. Microsc., G.W. Bailey, ed., San Francisco Press, San Francisco: 954.

Hainfeld, J. F., Sprinzl, M., Mandiyan, V., Tumminia, S. J., and Boublik, M. Localization of a specific nucleotide in yeast $t R N A$ by scanning transmission electron microscopy using an undecagold cluster. J. Struct. Biol. 107, 1-5 (1991).

Hainfeld, J. F. 1992. Site specific cluster labels. Ultramicroscopy, 46: 135.

Hainfeld, J. F., and Furuya, F. R. 1992. A 1.4-nm gold cluster covalently attached to antibodies improves immunolabeling. L. Histochem. Cytochem. 40: 177.

Hainfeld, J.F., Furuya, F.R., Carbone, K., Simon, M., Lin, B., Braig, K. Horwich, A.L., Safer, D., Blechschmidt, B., Sprinzl, M., Ofengand, J., and Boublik, M. 1993. High resolution gold labeling. In Proc. 51st Ann. Meet. Micros. Soc. Amer., G.W. Bailey and C.L. Rieder, eds., San Francisco Press, San Francisco: 330.

Hayat, M.A., ed. 1989. In Colloidal gold: Principles, methods, and applications. Vol. 1, Academic Press, San Diego, pp. 177, 225, 270, 212, 218, 307, 503.

Holgate, C.S., Jackson, P., Cowen, P.N., and Bird, C.C. 1983. Immunogold-silver staining: New method of immunostaining with enhanced sensitivity. $L$ Histochem. Cytochem. 31: 938.

Horisberger, M., and Clerc, M.F. 1985. Labelling of colloidal gold with protein A. A quantitative study. Histochem. 82: 219.

Hsu, Y.-H. 1984. Immunogold for detection of antigen on nitrocellulose paper. Anal. Biochem. 142: 221.

McPartlin, M., Mason, R., and Malatesta, I. 1969. Novel cluster complexes of gold(0)-gold(1). J. Chem. Soc., Chem. Commun.: 334.

Milligan, R.A., Whittaker, M., and Safer, D. 1990. Molecular structure of F-actin and location of surface binding sites. Nature $\underline{348: 217 .}$ 
Moeremans, M., Daneels, G., Van Dijck, A., Langanger, G., De Mey, J. 1984. Sensitive visualization of antigen-antibody reactions in dot and blot immune overlay assays with immunogold and immunogold/silver staining. L. Immunol. Methods 74: 353.

Pollard-Knight, D., Simmonds, A.C., Schaap, A.P., Akhavan, H., and Brady, M.A.W. 1990. Nonradioactive DNA detection on Southern blots by enzymatically triggered chemiluminescence. Anal. Biochem. 185: 353.

Reardon, J.E. and Frey, P.A. 1984. Synthesis of undecagold cluster molecules as biochemical labeling reagents. 1. Monoacyl and mono[N(succinimidooxy)succinyl] undecagold clusters. Biochemistry 23: 3849.

Safer, D., Bolinger, L., and Leigh, J.S. 1986. Undecagold clusters for site-specific labeling of biological macromolecules: simplified preparation and model applications. L. Inorg. Biochem. 26: 77.

Stierhof, Y.-D., Humbel, B.M., Hermann, R., Otten, M.T., and Schwarz, H. 1992. Direct visualization and silver enhancement of ultra-small antibody-bound gold particles on immunolabeled ultrathin resin sections. Scanning Microscopy $\underline{6}$ : 1009.

Skutelsky, E. and Roth, J. 1986. Cationic colloidal gold-a new probe for the detection of anionic cell surface sites by electron microscopy. I. Histochem. Cytochem. 34: 693.

Vandré, D.D., and Burry, R.W. 1992. Immunoelectron microscopic localization of phosphoproteins associated with the mitotic spindle. L. Histochem. Cytochem. 40: 1837.

Wall, J. S., Hainfeld, J. F., Bartlett, P. A., and Singer, S. J. 1982. Observation of an undecagold cluster compound in the scanning transmission electron microscope. Ultramicroscopy 8 : 397 .

Weinstein, S., Jahn, W., Hansen, H., Wittmann, H.G., and Yonath, A. 1989. Novel procedures for derivatization of ribosomes for crystallographic studies. I. Biol. Chem. 264: 19138.

Weiser, H.B. 1933. In Inorganic Colloid Chemistry, Vol. 1. pp. 21-57. Wiley, New York.

Wilkens, S. and Capaldi, R.A. 1992. Monomaleimidogold labeling of the $\gamma$ subunit of the Escherichia coli $\mathrm{F}_{1}$ ATPase examined by cryoelectron microscopy. Arch. Biochem. Biophys. 299:105. 
Wu, B., Mahony, J.B., and Chernesky, M.A. 1990. A new immune complex dot assay for detection of rotavirus antigen in faeces. L. Virolog. Meth. 29: 157.

\section{Yang, H., Reardon, J.E., and Frey, P.A. 1984. Synthesis of undecagold cluster molecules as biochemical labeling reagents. 2. Bromoacetyl and maleimido undecagold clusters. Biochemistry 23: 3857.}

\section{DISCLAIMER}

This report was prepared as an account of work sponsored by an agency of the United States Government. Neither the United States Government nor any agency thereof, nor any of their employees, makes any warranty, express or implied, or assumes any legal liability or responsibility for the accuracy, completeness, or usefulness of any information, apparatus, product, or process disclosed, or represents that its use would not infringe privately owned rights. Reference herein to any specific commercial product, process, or service by trade name, trademark, manufacturer, or otherwise does not necessarily constitute or imply its endorsement, recommendation, or favoring by the United States Government or any agency thereof. The views and opinions of authors expressed herein do not necessarily state or reflect those of the United States Government or any agency thereof. 


\section{FIGURE LEGENDS}

Fig. 1. Structure of the undecagold cluster.

Fig. 2. Dark field scanning transmission electron micrograph (STEM) of the undecagold clusters on a thin carbon film. Bright dots are the eleven gold atom cores that have a $0.8 \mathrm{~nm}$ diameter. Since it is a compound, there is complete uniformity of size. Full width $0.128 \mu \mathrm{m}$.

Fig. 3. Covalent coupling of undecagold to the hinge thiol of an Fab' fragment. Fig. 4. Dark field STEM micrograph of Fab' fragments labeled with undecagold. Large arrow points to whitish area that is the (unstained) Fab' fragment; small arrow points to an undecagold cluster attached to its hinge region. Full width $0.128 \mu \mathrm{m}$.

Fig. 5. Darkfield STEM micrograph of Nanogold $1.4 \mathrm{~nm}$ clusters (bright dots). Full width $0.128 \mu \mathrm{m}$.

Fig. 6. Darkfield STEM micrograph of Nanogold (bright dots) showing a microcrystal. Full width $0.064 \mu \mathrm{m}$.

Fig. 7. Covalent coupling scheme of Nanogold to a protein thiol showing dimensions of the gold and distance from thiol.

Fig. 8. Dark field STEM micrograph of Fab' fragments labeled with Nanogold. Large arrow points to whitish area that is the (unstained) Fab' fragment; small arrow points to a Nanogold cluster attached to its hinge region. Full width 0.128 $\mu \mathrm{m}$.

Fig. 9. Spectral changes of the silver enhancer (LI Silver, Nanoprobes) alone over time. The spectral range is 330 to $820 \mathrm{~nm}$. The sample was scanned once per minute over a $30 \mathrm{~min}$ time range; each scan is represented by a one line spectrum. The first scan is the lowest one with the least absorbance. As can be seen, many scans nearly overlap during the first few minutes, but become further apart as time progresses (the uppermost scans) indicating an acceleration of development.

Fig. 10. Absorbence at particular wavelengths for the silver enhancer alone plotted versus time (in seconds; full width is $30 \mathrm{~min}$ ). Top light trace is the absorbancy of the average of 430 to $450 \mathrm{~nm}$, thus picking up the $440 \mathrm{~nm}$ peak that develops (see Fig. 9). The lower light trace is the absorbance at $810 \mathrm{~nm}$ (800 to $820 \mathrm{~nm}$ data averaged), showing little change or coating of the cuvette walls with silver over this period. The darker trace is the difference between these curves. Fig. 11. Silver enhancement of Nanogold tracked by uv-vis spectral changes. Each spectrum is $1 \mathrm{~min}$ apart. An initial peak appears at $\sim 460 \mathrm{~nm}$, shifts to $\sim 430$ then back to $450 \mathrm{~nm}$. Nanogold concentration was $2.2 \times 10^{-6} \mathrm{M}$. Concentration of silver developer (LI Silver, Nanoprobes) was the same as used in the control shown in Figs. 9 and 10.

Fig. 12. Development of Nanogold $\left(2.2 \times 10^{-6} \mathrm{M}\right)$ from Fig. 11 replotted using the change at a particular wavelength vs. time. Top left light line is $440 \mathrm{~nm}$ (430 to 450 averaged) and rightmost light line is at $810 \mathrm{~nm}$ ( 800 to 820 averaged). Full 
time scale is $540 \mathrm{sec}(9 \mathrm{~min})$. Heavy line is the difference between the other two plots.

Fig. 13. Development of Nanogold $\left(2.9 \times 10^{-7} \mathrm{M}\right)$ monitored by absorbance at 440 $\mathrm{nm}$ (top light line), $810 \mathrm{~nm}$ (lower light line), and the difference of these graphs (dark line). Time scale is in sec, $1140 \mathrm{max}(19 \mathrm{~min})$.

Fig. 14. Silver enhancement of a very dilute Nanogold solution $\left(1.7 \times 10^{-9} \mathrm{M}\right)$ monitored by uv-vis spectroscopy. Spectra are recorded every $1 \mathrm{~min}$. A major peak at $450 \mathrm{~nm}$ and a minor one at $\sim 710 \mathrm{~nm}$ appear.

Fig. 15. Data from Fig. 14 plotted to show absorbance at specific wavelengths vs. time. Top trace is $445 \mathrm{~nm}$ ( 440 to $450 \mathrm{~nm}$ data averaged), bottom trace is at 810 $\mathrm{nm}$ ( 800 to $820 \mathrm{~nm}$ data averaged); bold trace is a difference plot. Full width 1800 $\mathrm{sec}(30 \mathrm{~min})$.

Fig. 16. Silver enhancement of a very dilute Nanogold solution $\left(1.7 \times 10^{-9} \mathrm{M}\right)$ compared to the silver enhancement solution (LI Silver) alone. The optical density at $440 \mathrm{~nm}$ was monitored over time. Significant signal is seen after 5 to 10 minutes for the Nanogold, and would correspond to a detection of $\sim 10^{-13}$ moles in a $50 \mu$ l cuvette cell.

Fig. 17. Undecagold spectra taken at 1 sec intervals during silver enhancement. The undecagold concentration was $1.2 \times 10^{-5} \mathrm{M}$. A distinct peak at $370 \mathrm{~nm}$ appears.

Fig. 18. Undecagold silver enhancement (same as for Fig. 17) monitored over time using the absorbance at $372 \mathrm{~nm}$ ( 370 to $374 \mathrm{~nm}$ data averaged, top light trace), $810 \mathrm{~nm}$ ( 800 to $820 \mathrm{~nm}$ averaged, lower light trace) and their difference (bold line). Time period is $1380 \mathrm{sec}(15 \mathrm{~min})$.

Fig. 19. Development of Nanogold and undecagold as assayed by absorbance in solution. The results from Figs. 10, 12, 13, 15. and 18 are here plotted on the same scale. The absorbance difference of $440 \mathrm{~nm}$ minus $810 \mathrm{~nm}$ is used for all samples except the undecagold, which is $370 \mathrm{~nm}$ minus $810 \mathrm{~nm}$.

Fig. 20. Spectra of $3 \mathrm{~nm}$ colloidal gold as it is silver enhanced in solution. Spectra are recorded every $1 \mathrm{~min}$. Colloidal gold concentration was $5 \times 10^{-7} \mathrm{M}$, and included 1\% BSA for stabilization.

Fig. 21. Silver enhancement of $3 \mathrm{~nm}$ colloidal gold (same as Fig. 20) replotted to show the change in absorbance at $440 \mathrm{~nm}$ with time (top light trace), $810 \mathrm{~nm}$ (bottom light trace) and the difference between these two (bold trace). Time is over $840 \mathrm{sec}$ (14 $\mathrm{min})$.

Fig. 22. Spectra of $15 \mathrm{~nm}$ colloidal gold as it is silver enhanced in solution.

Spectra are recorded every $1 \mathrm{~min}$. Colloidal gold concentration was $1.3 \times 10^{-9} \mathrm{M}$, and included $1 \%$ BSA for stabilization.

Fig. 23. Silver enhancement of $15 \mathrm{~nm}$ colloidal gold (same a Fig. 22) replotted to show the change in absorbance at $440 \mathrm{~nm}$ with time (top light trace), $810 \mathrm{~nm}$ (bottom light trace) and the difference between these two (bold trace). Time is over $600 \mathrm{sec}(10 \mathrm{~min})$.

Fig. 24. Spectra of $15 \mathrm{~nm}$ colloidal gold as it is silver enhanced in solution.

Spectra are recorded every $1 \mathrm{~min}$. Colloidal gold concentration was $3.3 \times 10^{-11} \mathrm{M}$, and included $0.025 \%$ BSA for stabilization. 
Fig. 25. Silver enhancement of $15 \mathrm{~nm}$ colloidal gold (same a Fig. 24) replotted to show the change in absorbance at $440 \mathrm{~nm}$ with time (top light trace), $810 \mathrm{~nm}$ (bottom light trace) and the difference between these two (bold trace). Time is over $1260 \mathrm{sec}(21 \mathrm{~min})$.

Fig. 26. Transmission electron micrograph of undecagold clusters silver enhanced for $15 \mathrm{~min}$. Undecagold concentration was $1.2 \times 10^{-5} \mathrm{M}$ and LI Silver (Nanoprobes) was used as the developer. Many particles are in the $10 \mathrm{~nm}$ range. Full width $700 \mathrm{~nm}$.

Fig. 27. Transmission electron micrograph of Nanogold clusters silver enhanced for $3 \mathrm{~min}$. Nanogold concentration was $7 \times 10^{-6} \mathrm{M}$ and IntenSE M (Amersham) was used as the developer. Many particles are in the $20 \mathrm{~nm}$ range. Full width $700 \mathrm{~nm}$.

Fig. 28. Transmission electron micrograph of Nanogold-Fab' (GAM) targeting a monoclonal antibody to synaptophysin in a PC12 cell neurite. Large arrows indicate silver enhanced gold located on the membranes of a cluster of synaptic vesicles. Small arrows indicate labeling on individual small clear vesicles. Note the excellent structural preservation and specific labeling. PC12 cells were grown in culture in a monolayer and treated with nerve growth factor. After fixing and permeabilizing (with $0.1 \%$ saponin), primary and secondary antibody incubations were done for $1 \mathrm{hr}$. each, then silver enhanced with HQ Silver (Nanoprobes, Inc.) for $4 \mathrm{~min}$. Poststaining was with $\mathrm{OsO}_{4}$ and uranyl acetate, and subsequent embedding was in Epon. Silver spots show a relatively uniform diameter of $\sim 10 \mathrm{~nm}$. Full width $1.35 \mu \mathrm{m}$. This work was done by Dr. Susan J.-H. Tao-Cheng, NINDS EM Facility, Laboratory of Neurobiology, NINDS/NIH.

Fig. 29. Transmission electron micrograph showing GABA-containing terminals (asterisks) forming symmetrical synaptic specialisations (arrows) with dendrites (D) in the thoracic spinal cord of the rat. After embedding in Durcupan (Fluka) and sectioning, immunolocalization was done by incubating with GABA antiserum (Incstar, 1:2000, $4^{\circ} \mathrm{C}, 18 \mathrm{hrs),} \mathrm{Nanogold} \mathrm{(goat} \mathrm{anti-rabbit,} \mathrm{1:40,} \mathrm{room}$ temperature, $90 \mathrm{~min}$ ), and intensified with HQ Silver (Nanoprobes) for $6 \mathrm{~min}$. Counterstaining was with lead citrate. There is excellent structural preservation and the silver enhanced gold particles are $\sim 20 \mathrm{~nm}$ in size. This work was done by Dr. Sarah Bacon, Oxford University, Department of Pharmacology, U.K. Fig. 30. Light micrograph of two neuroblastoma cells (large arrows) immunostained for a nuclear protein using Nanogold-Fab'. The cell boundary and cytoplasm are very light since the cytoplasm is unstained. After incubation with the primary monoclonal and then goat anti-mouse Fab'-Nanogold, silver enhancement was done using LI Silver (Nanoprobes). Small arrows point to the intense nuclear staining. Full width $290 \mu \mathrm{m}$. This work was done by Dr. Yair Gazitt, Bone Marrow Purging Laboratory, University of Florida College of Medicine.

Fig. 31 A. Light micrograph of spindle microtubules labeled with a monoclonal anti-tubulin antibody, followed by Nanogold-Fab', and silver enhanced. LLC-PK cells were grown in monolayer culture, fixed with glutaraldehyde $(0.7 \%, 15 \mathrm{~min})$, permeablized with $0.1 \%$ saponin, incubated with anti-tubulin antibodies (1:250, Amersham) for $1 \mathrm{hr}$ at $37^{\circ}$, rinsed, then incubated with anti-mouse Nanogold- 
Fab' (1:50, Nanoprobes) for $1 \mathrm{hr}$ at $37^{\circ}$. Samples were post-fixed, silver enhanced with a $\mathrm{N}$-propyl gallate enhancer for $\sim 9 \mathrm{~min}$, osmicated $\left(0.1 \% \mathrm{OsO}_{4}, 30 \mathrm{~min}\right)$, dehydrated, embedded in Epon, and sectioned. Intense staining was observed. Full width $95 \mu \mathrm{m}$.

B. Same preparation as described in A, except that AuroProbe One goat antimouse was used (1:50, Amersham). Only weak staining was observed. Full width $95 \mu \mathrm{m}$. This work was done by Drs. Dale Vandré and Richard Burry, Department of Cell Biology, Neurobiology, and Anatomy, The Ohio State University.

Fig. 32. Dilutions of Nanogold (A) and undecagold (B) applied to nitrocellulose paper, dried, and silver enhanced. Amount in upper left box of each blot was 1 picomole per spot (applied in $1 \mu \mathrm{l}$ ). Dilutions were made in water, each box representing a 10 fold dilution, and duplicate samples were spotted in each box. Lower right box was diluent only (in this case water). Development was for 30 min. Actual blots were whiter, but overexposed prints were made to improve visibility of spots. Frequently, the faintest spot must be detected with a hand lens. The Nanogold developed in all 8 boxes, corresponding to detection of 10-19 moles. The silver enhanced undecagold was visible by eye only in 4 boxes, corresponding to $10^{-15}$ mole sensitivity.

Fig. 33. Immunodot blot with Nanogold-IgG (A) and undecagold-IgG (B). First, a mouse IgG was applied in 10 fold dilutions to the first 8 boxes (a duplicate spotted in each box), and buffer (the diluent, PBS) applied to the lower right box, dried, then blocked in BSA buffer (Moeremans et al., 1984). The highest concentration, in the upper left box, was $0.1 \mu \mathrm{g}$. The blots were then incubated with the goat anti-mouse gold conjugate for $1 \mathrm{hr}$ at room temperature, washed, and silver enhanced for $30 \mathrm{~min}$. Blots are printed darker than they were to improve visibility of spots. The Nanogold-IgG showed 5 boxes visible $\left(10^{-11} \mathrm{~g}\right.$ or $\sim^{-16}$ moles target detected), and the undecagold-IgG showed 2 boxes developing $\left(10^{-8} \mathrm{~g}\right.$ or $10^{-13}$ moles detected.

Fig. 34. Sensitive immunodot blot obtained with Nanogold anti-mouse Fab' to a mouse IgG target showing $0.1 \mathrm{pg}$ detection (arrow), corresponding to $6.7 \times 10^{-19}$ moles of target. $1 \mu$ l of mouse IgG (antigen target) was spotted onto nitrocellulose containing the following amounts (each box contains a duplicate spot): top row (of spots): $10 \mathrm{ng}, 2.5 \mathrm{ng}, 1 \mathrm{ng}, 0.25 \mathrm{ng}$; middle row: $100 \mathrm{pg}, 25 \mathrm{pg}$, $10 \mathrm{pg}, 2.5 \mathrm{pg}$; bottom row: $1 \mathrm{pg}, 0.25 \mathrm{pg}, 0.1 \mathrm{pg}$, buffer blank. Membrane was blocked with $4 \%$ BSA. Goat anti-mouse Fab'-Nanogold was incubated 2 hours, washed and developed $2 \times 15$ min with LI Silver. Buffer and non-specific antibody/antigen controls were blank.

Fig. 35. Plot of Nanogold stability upon heating. Degradation was monitored by following the optical density at $420 \mathrm{~nm}$. Solvents of PBS or $20 \mathrm{mM}$ phosphate, $\mathrm{pH} 7.4,0.5 \mathrm{M} \mathrm{NaCl}$ gave virtually the same results and were averaged. Fitted curves are shown, and values $>100 \%$ indicate experimental error.

Fig. 36. SDS polyacrylamide Phast gels of native and Nanogold labeled proteins, with development by Coomassie Blue or silver enhancement. Lane 1 is a protein molecular weight standard (values listed on left are in $\mathrm{kD}$ ), lane 2 is native Fab', 
lane 3 is Nanogold-Fab', lane 4 is $F\left(a b^{\prime}\right)_{2}$. Gels $A$ and $C$ are developed with Coomassie Blue and gels $B$ and $D$ are developed with a silver enhancer (LI Silver, Nanoprobes). A and B are gels of samples that were not heated before running, and $C$ and $D$ are gels of samples heated to $100^{\circ}$ in $1.3 \%$ SDS for $5 \mathrm{~min}$ before running. Gels A and B were identical except for staining, as were gels C and D. The unheated samples show native and Nanogold labeled Fab' to run anomalously, showing bands $>50 \mathrm{kD}$, whereas $\mathrm{F}\left(\mathrm{ab}^{\prime}\right)_{2}$ runs at $\sim 100 \mathrm{kD}$ as expected. After heating (gels $C$ and $D$ ), the Fab' runs as expected, showing bands at $50 \mathrm{kD}$, and single light or heavy chains at $25 \mathrm{kD}$. The Nanogold labeled Fab' bands are nearly indistinguishable from the native Fab' bands in this case (gel C, lanes 2 and 3). In all cases, the silver enhancement specifically developed the Nanogold labeled proteins selectively (gels B and D), and unlabeled proteins did not develop (gels B and D, lanes 1,2, and 4). In addition, Nanogold bands with silver enhancement were intense in $<5 \mathrm{~min}$, whereas Coomassie staining took 1 hour (followed by 1 hour of destaining). 


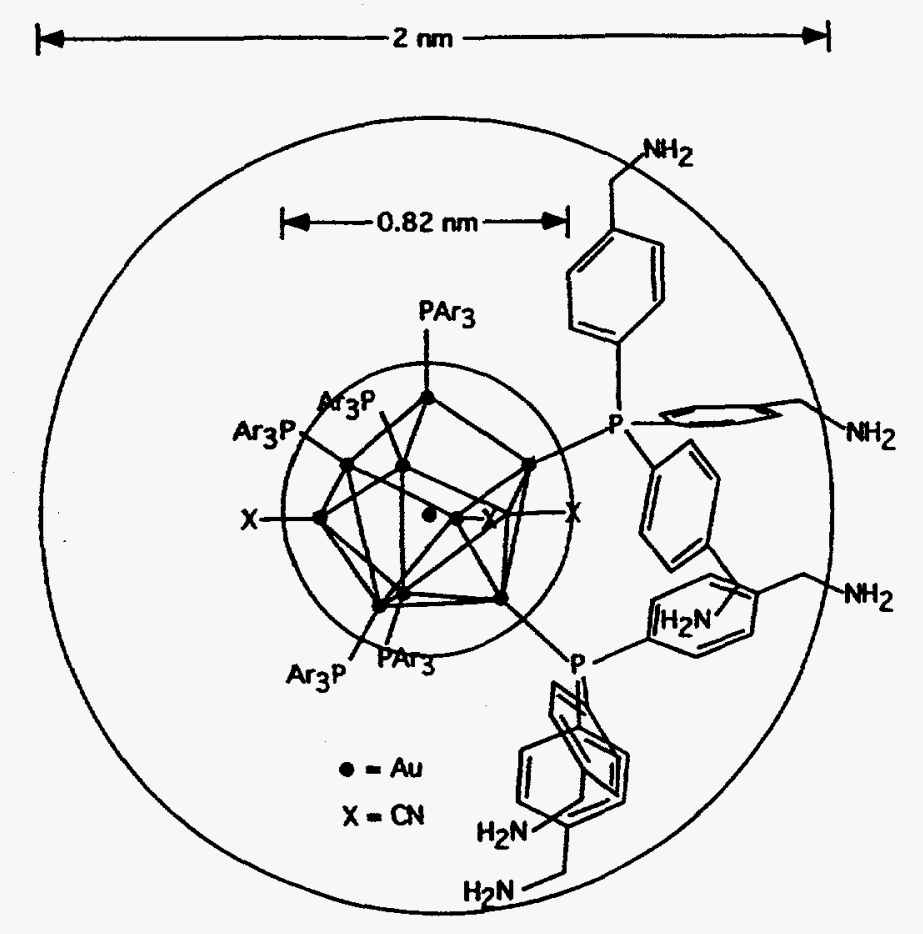

Fig. I Hainfeld 


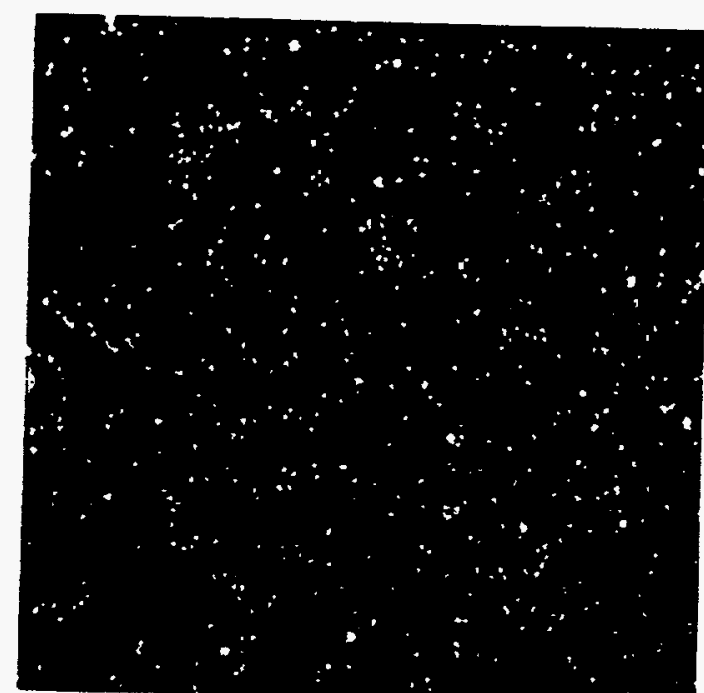




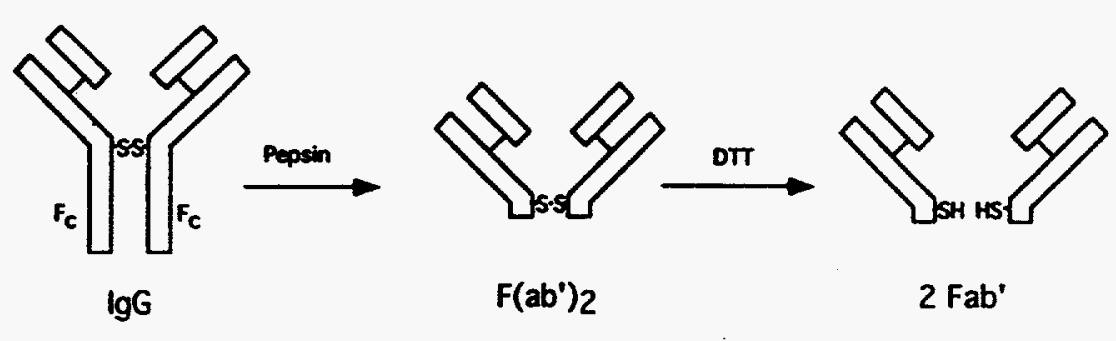

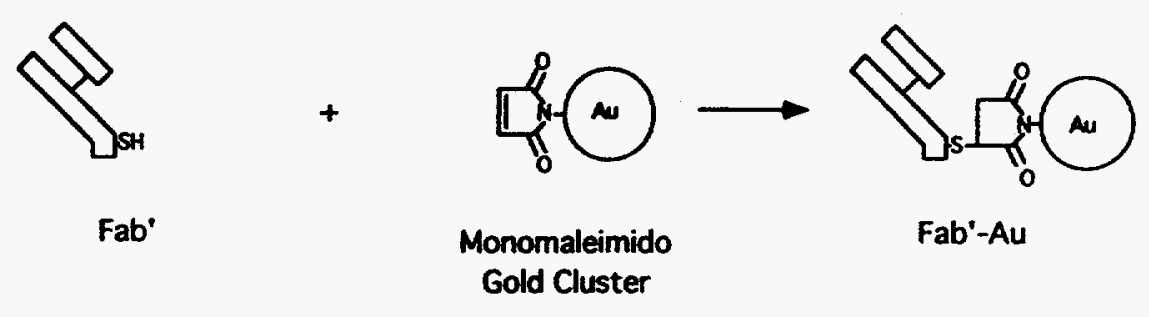

$5: 3$ 

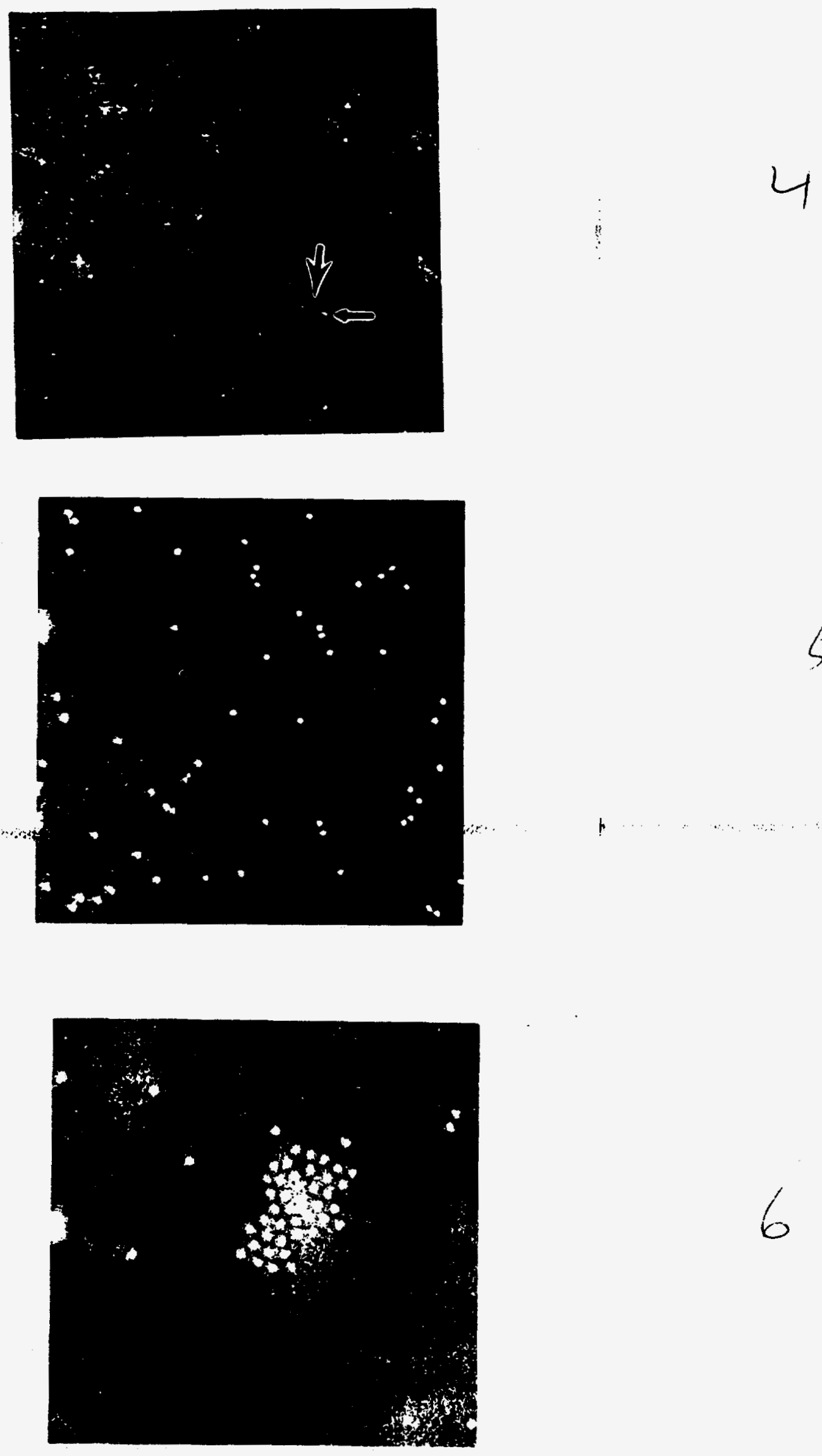

6 

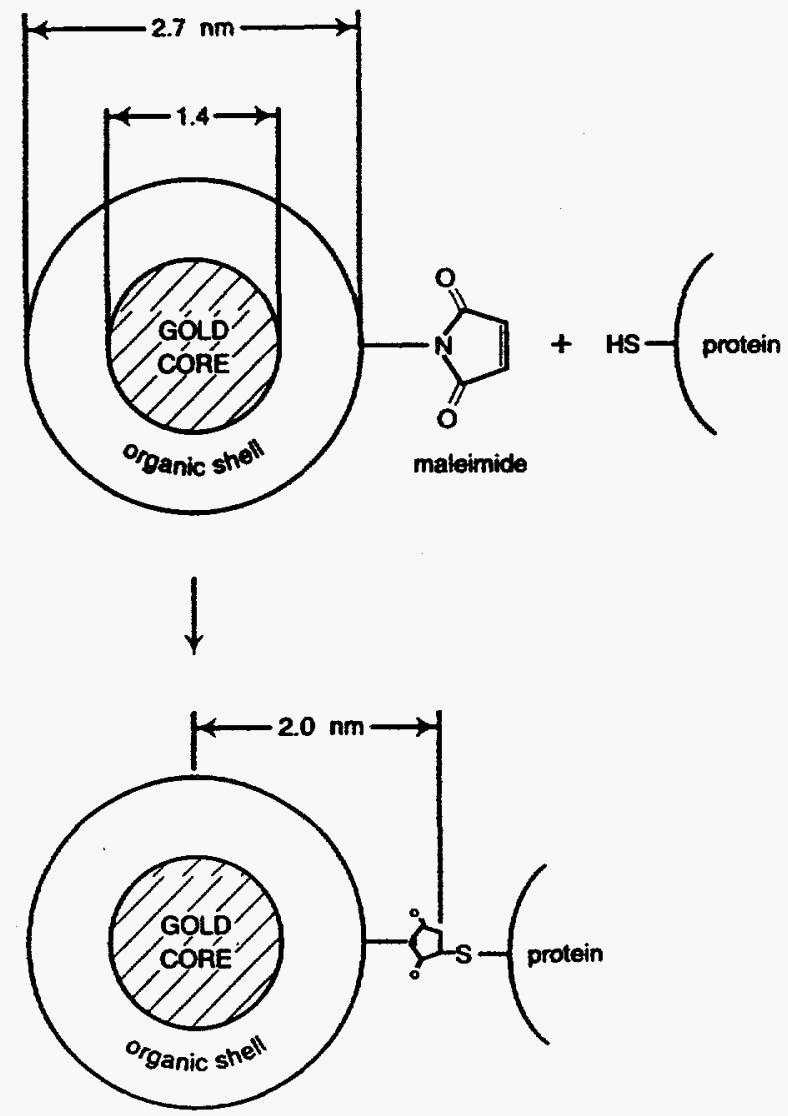

$$
5.7 \ldots d
$$




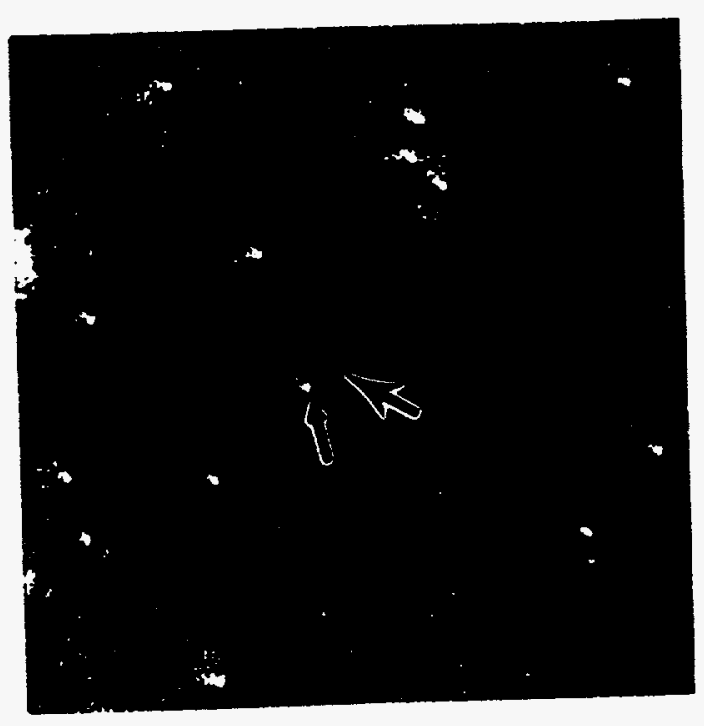

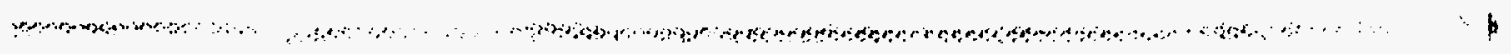

8 
$x_{2}+\infty$

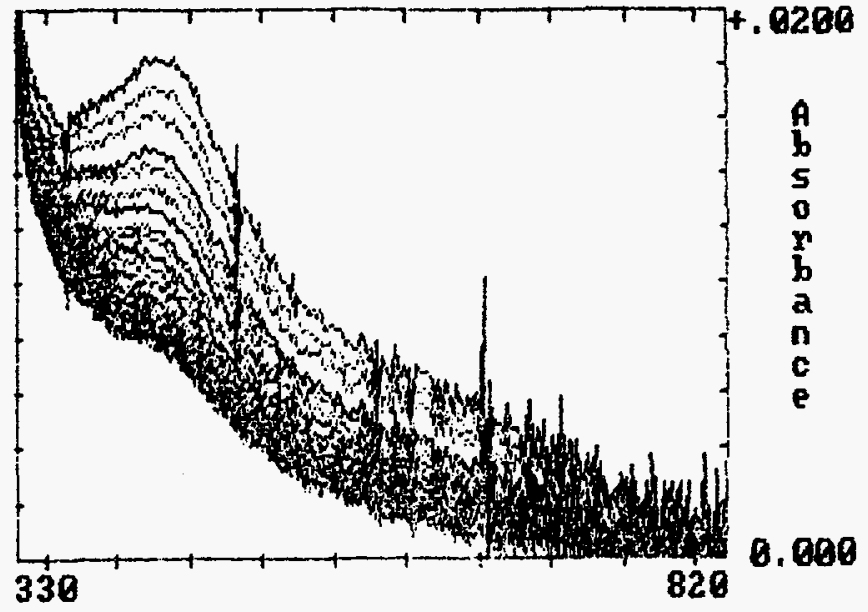

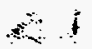

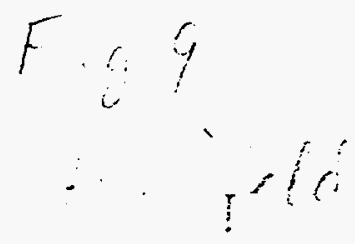



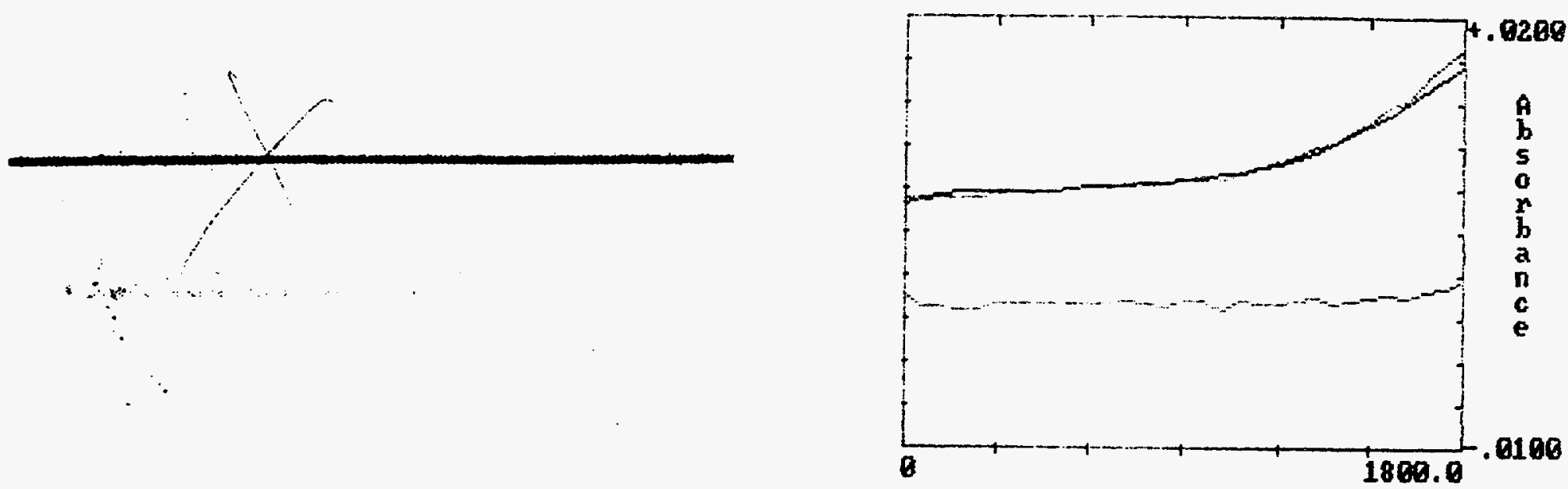

$\therefore+\cdots$

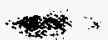

$$
\text { Fig } 10
$$


$\cdot 3$

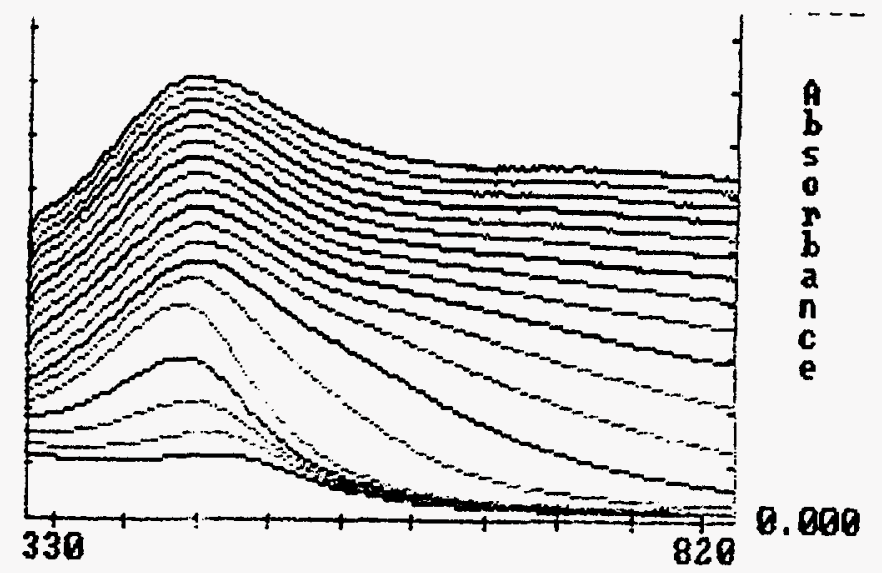

Fig II
Hainfeld 

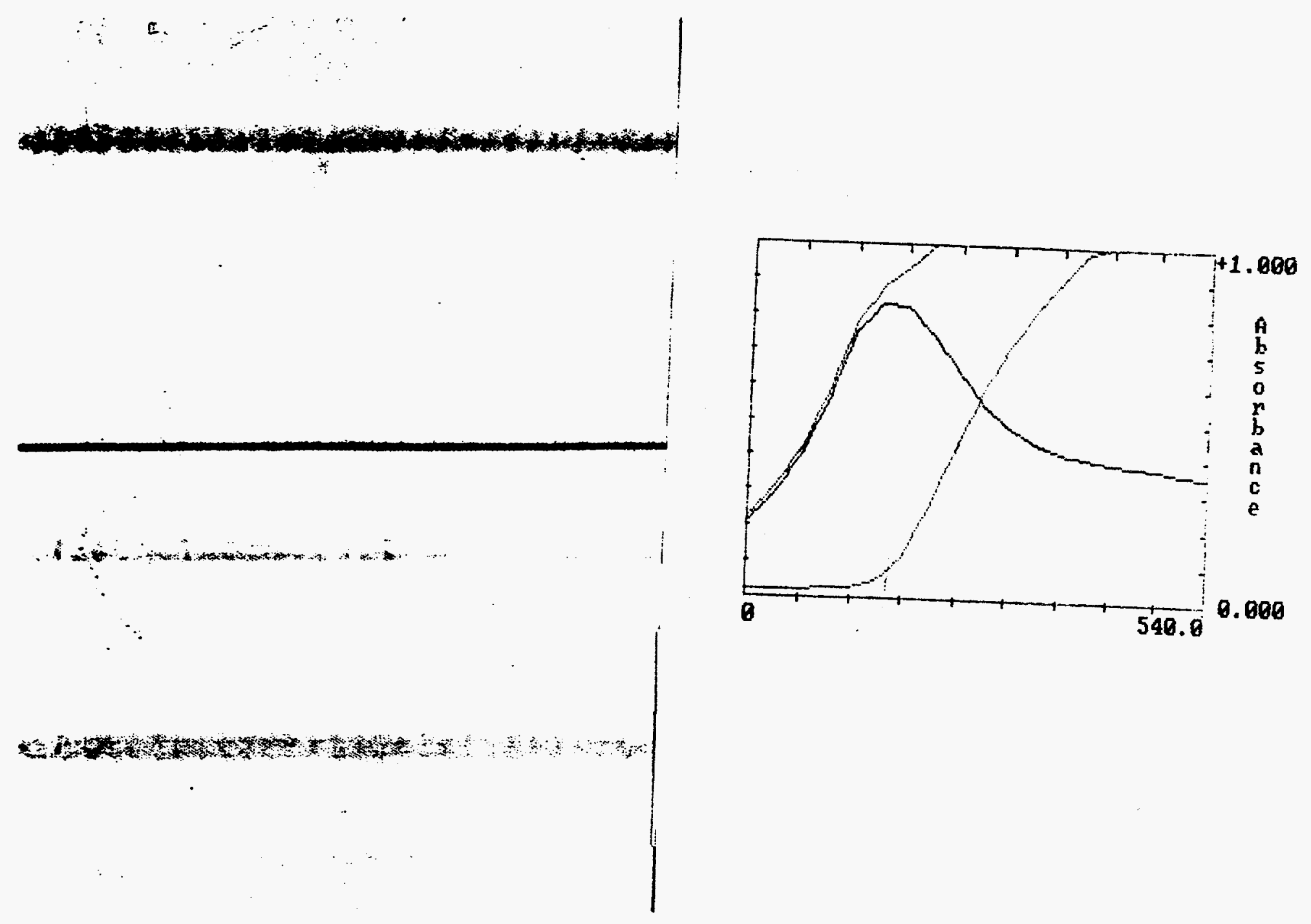

$$
5: 12
$$




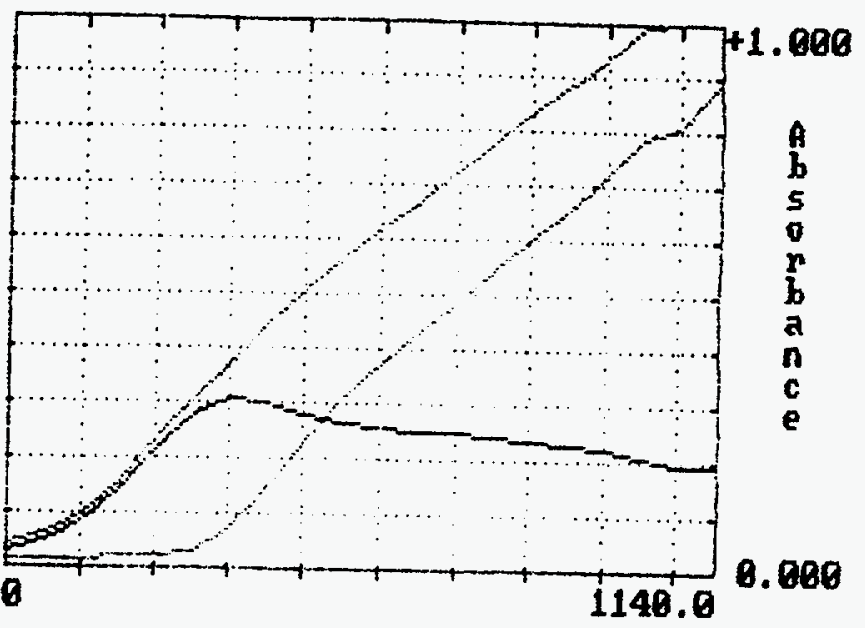

$\therefore 1$ a

$$
\begin{aligned}
& \text { F.g.13 } \\
& \text { Hampeles }
\end{aligned}
$$



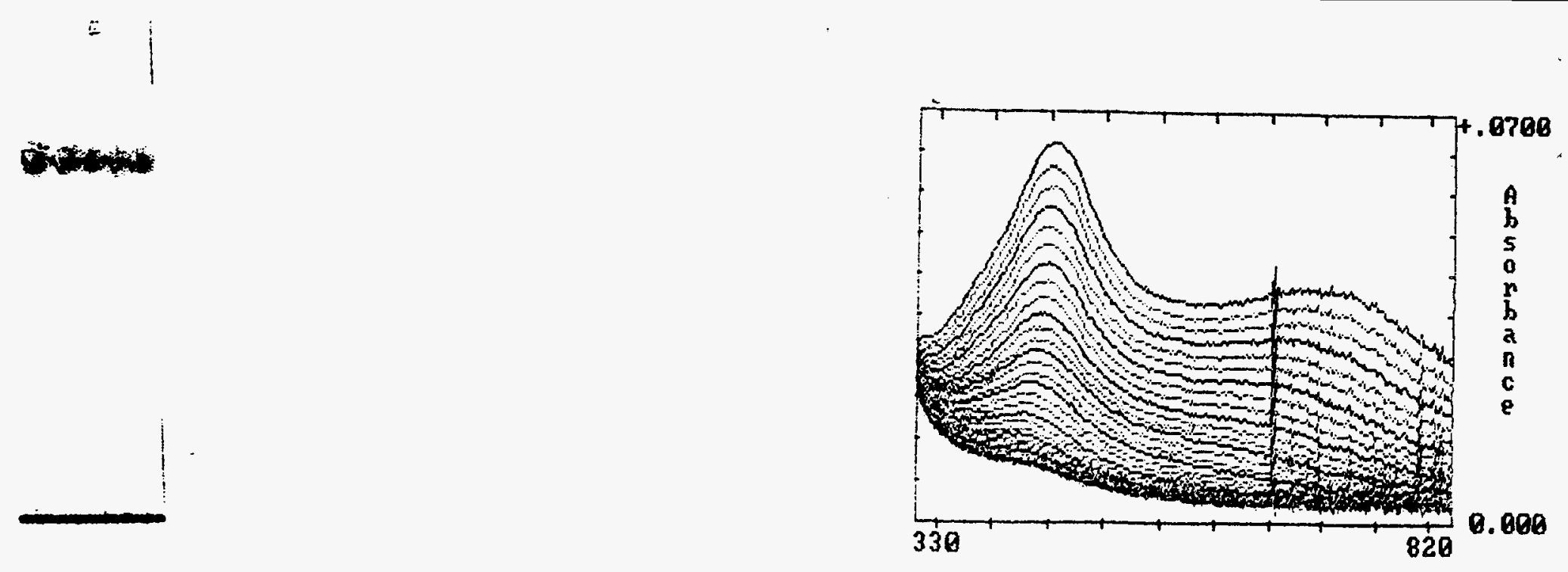

$$
\begin{aligned}
& \text { fug } 14 \\
& \text { Hainfeld }
\end{aligned}
$$


5

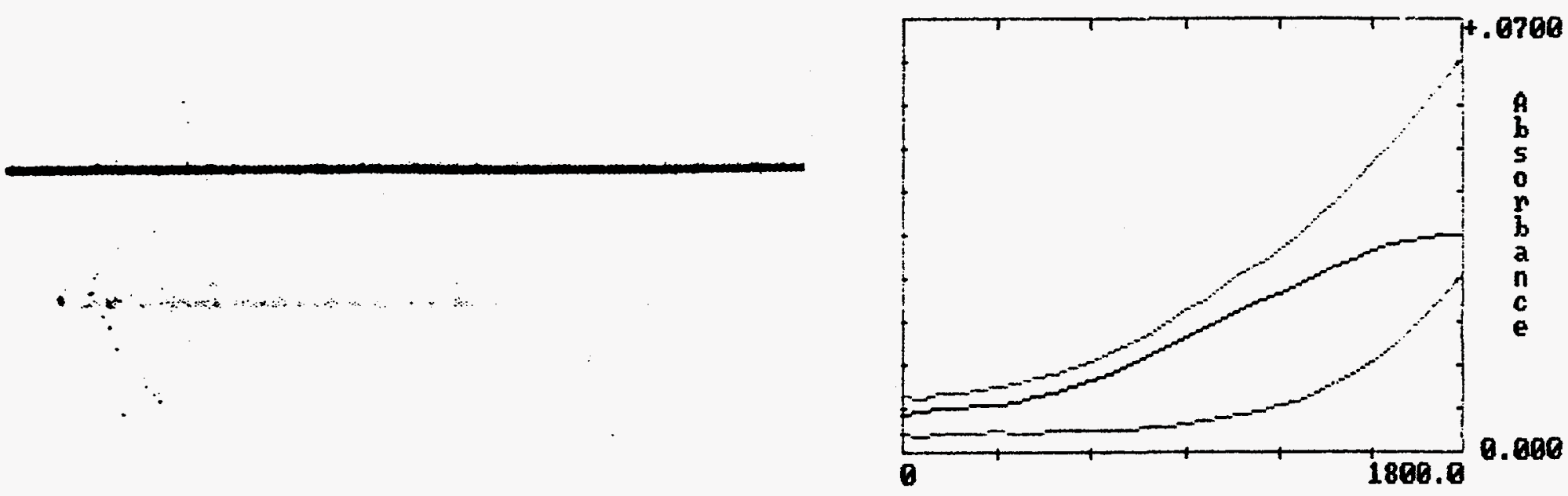

be 15
tingelo 

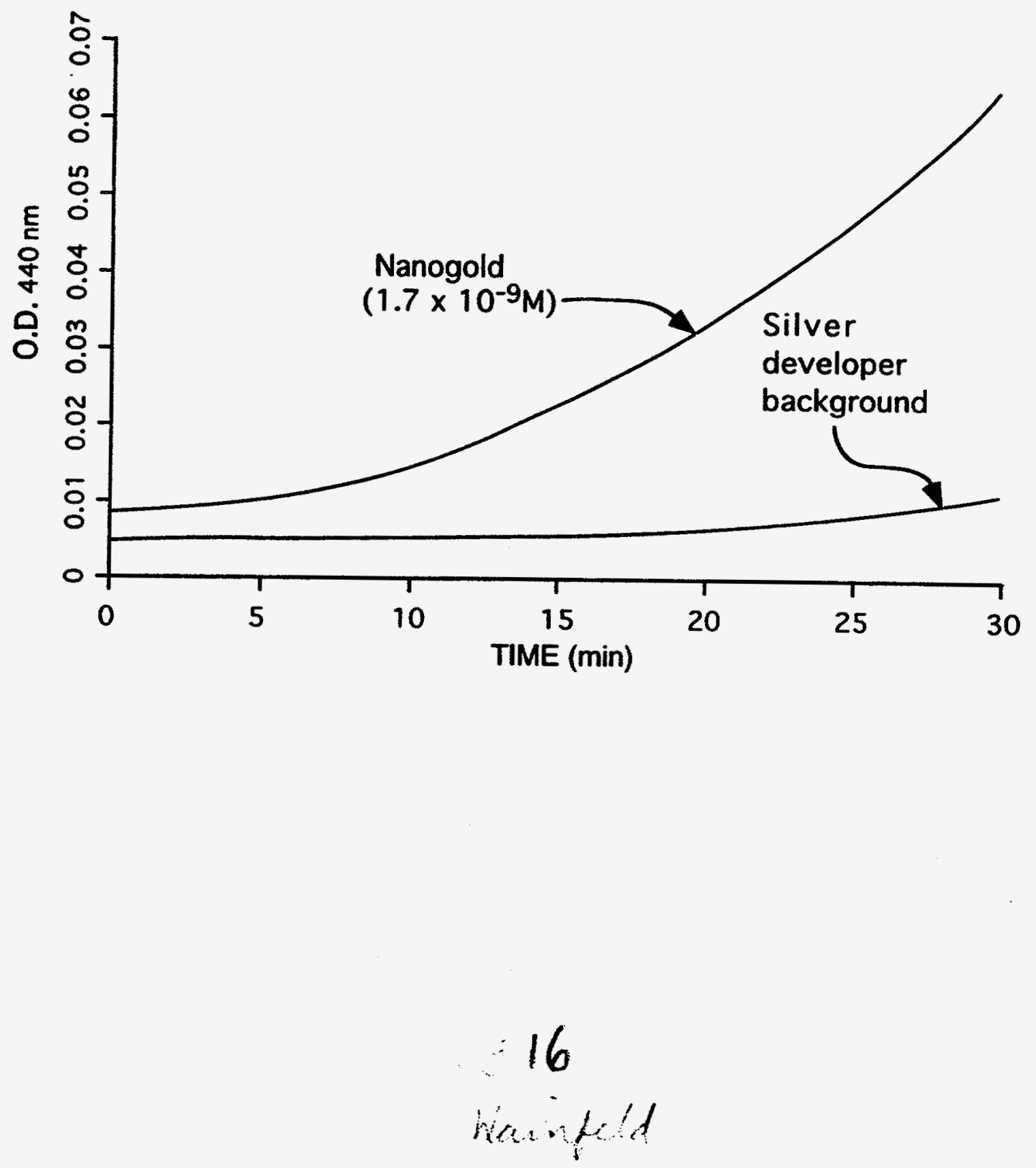
$\begin{array}{cc}3 \\ 3 & 9 \\ 3 & 0\end{array}$

prisis

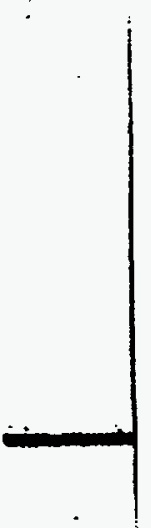

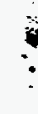

$\ddots$
$\ddots$
$\ddots$

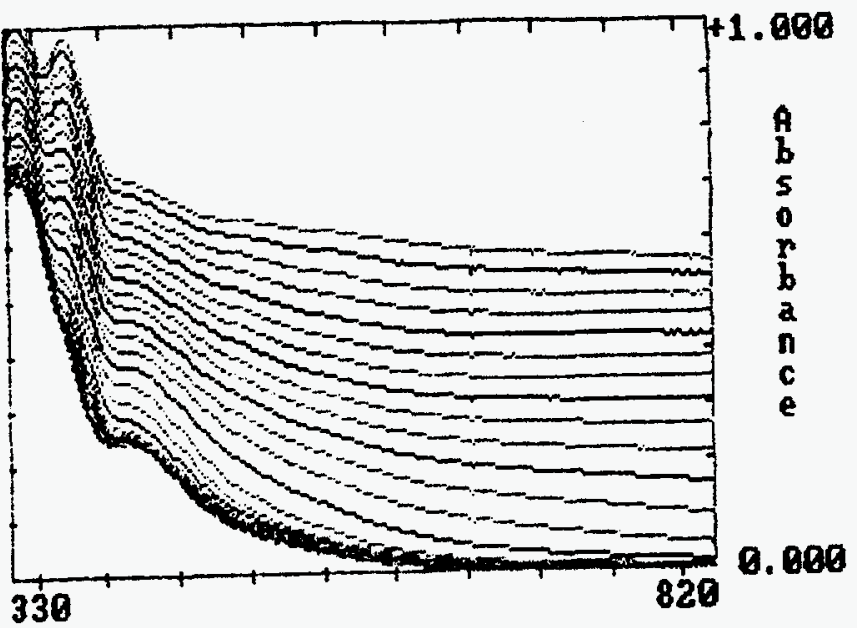

$F: 417$

thanfubl 
$+\vdots$

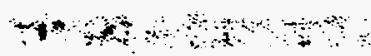

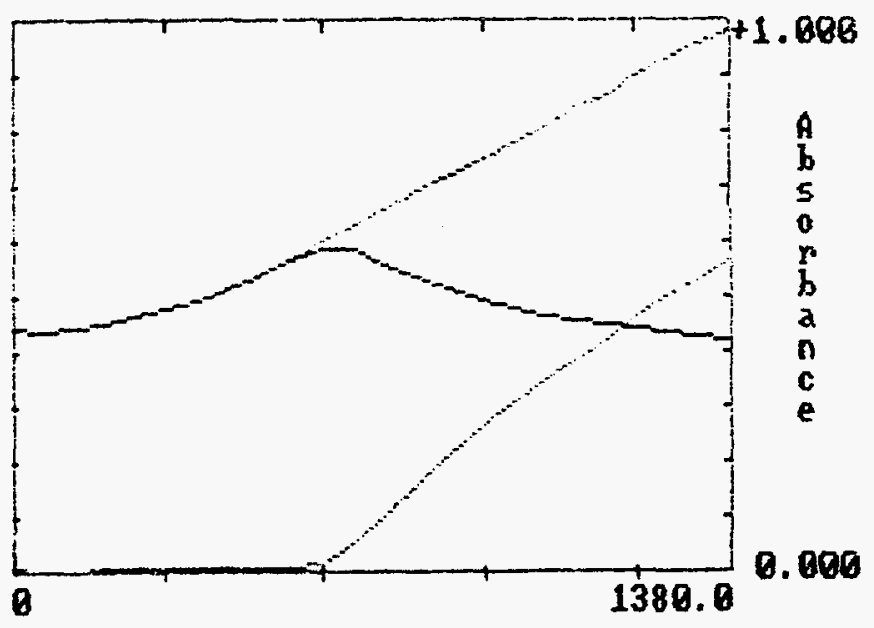

sorfeld 

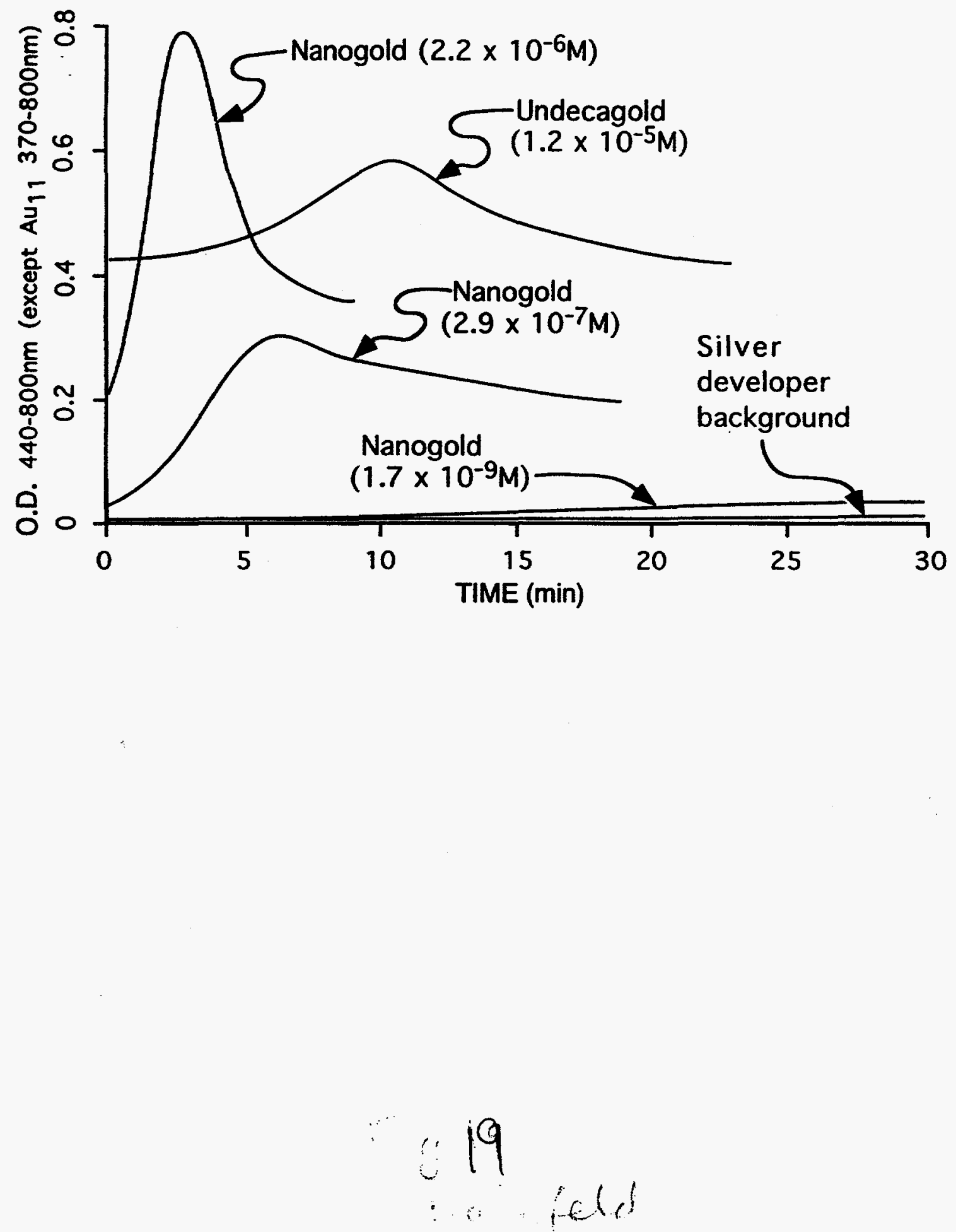


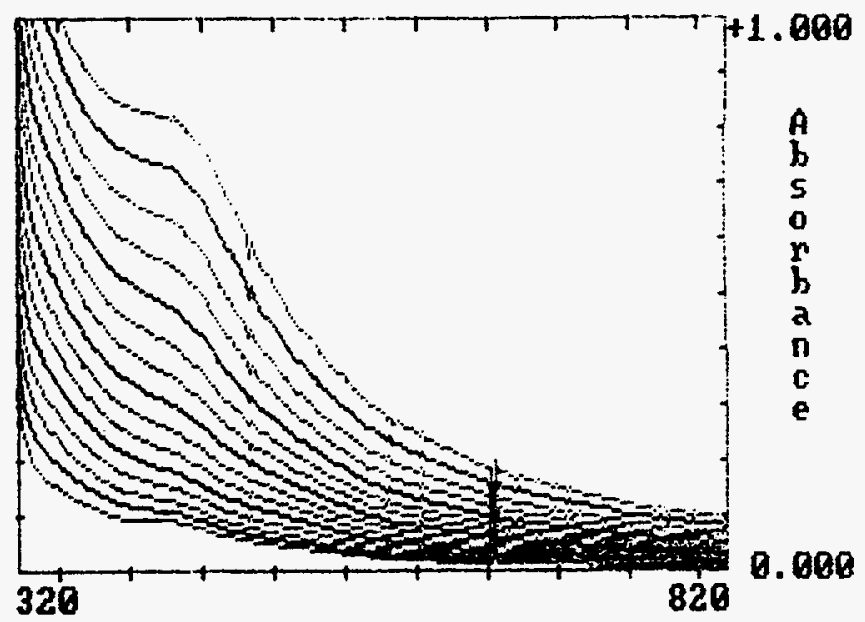

Fig 20
fia (e) 


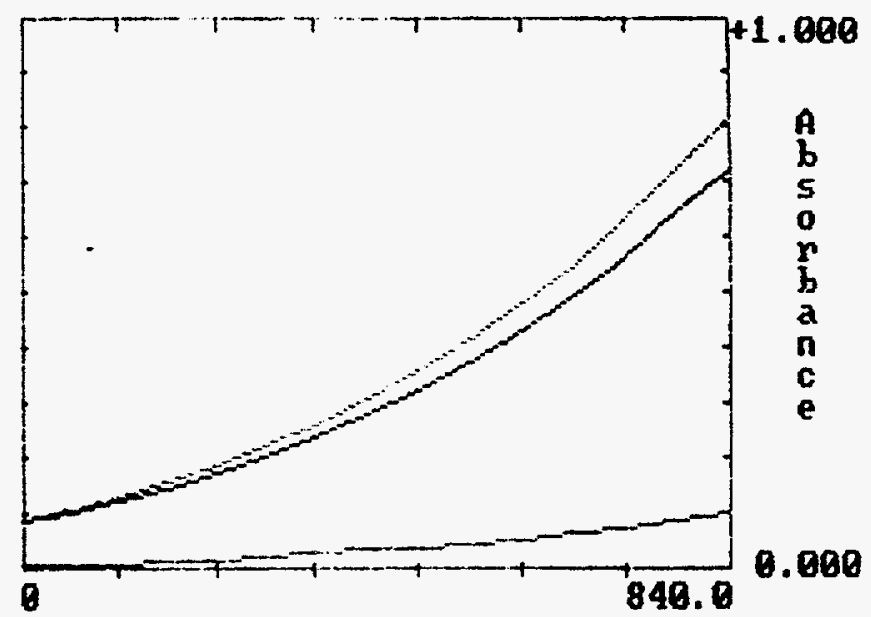

Feg 21

Hainfeld 


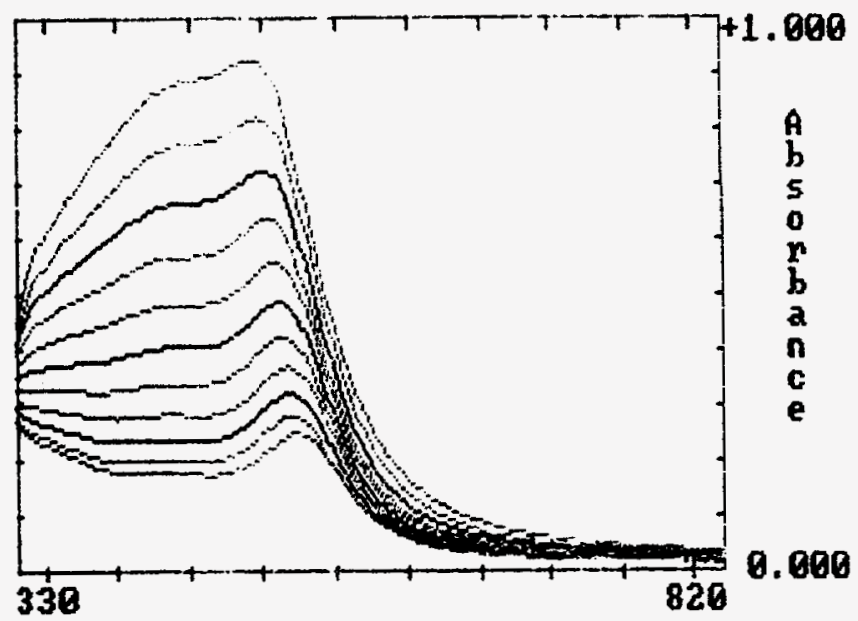

$$
\begin{aligned}
& =g_{22} \\
& \text { cunpled }
\end{aligned}
$$




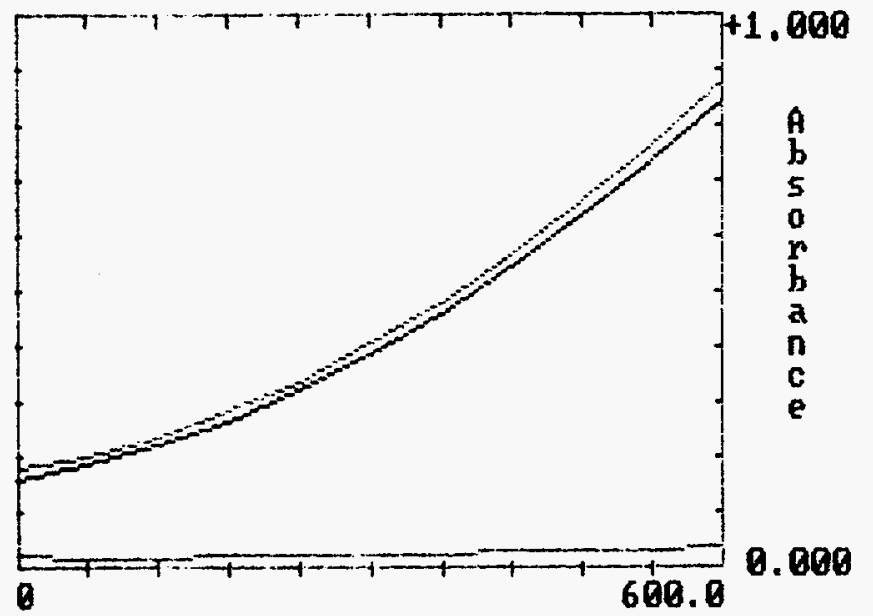

Fig 23
ramfod 


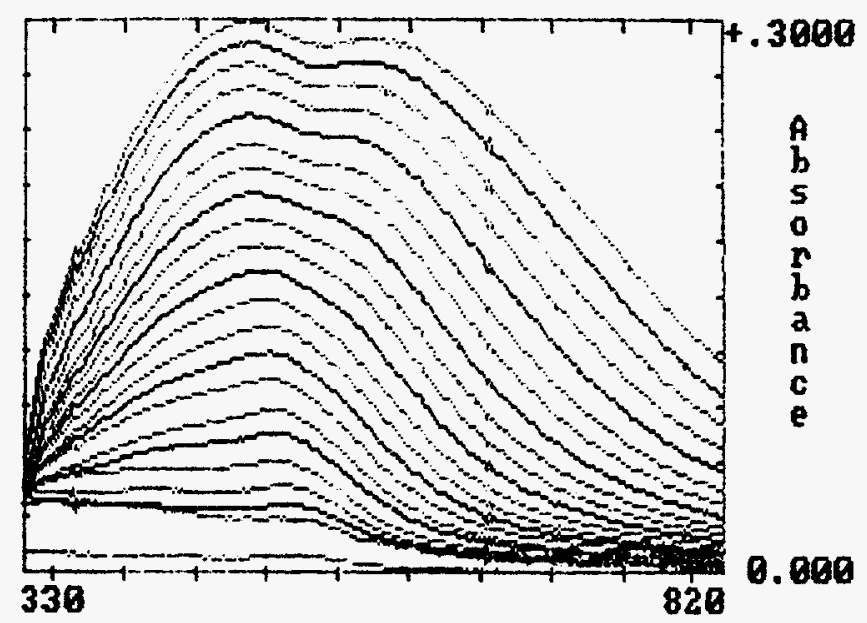

$$
\begin{aligned}
& \text { Fig } 24 \\
& \text { fla feld }
\end{aligned}
$$




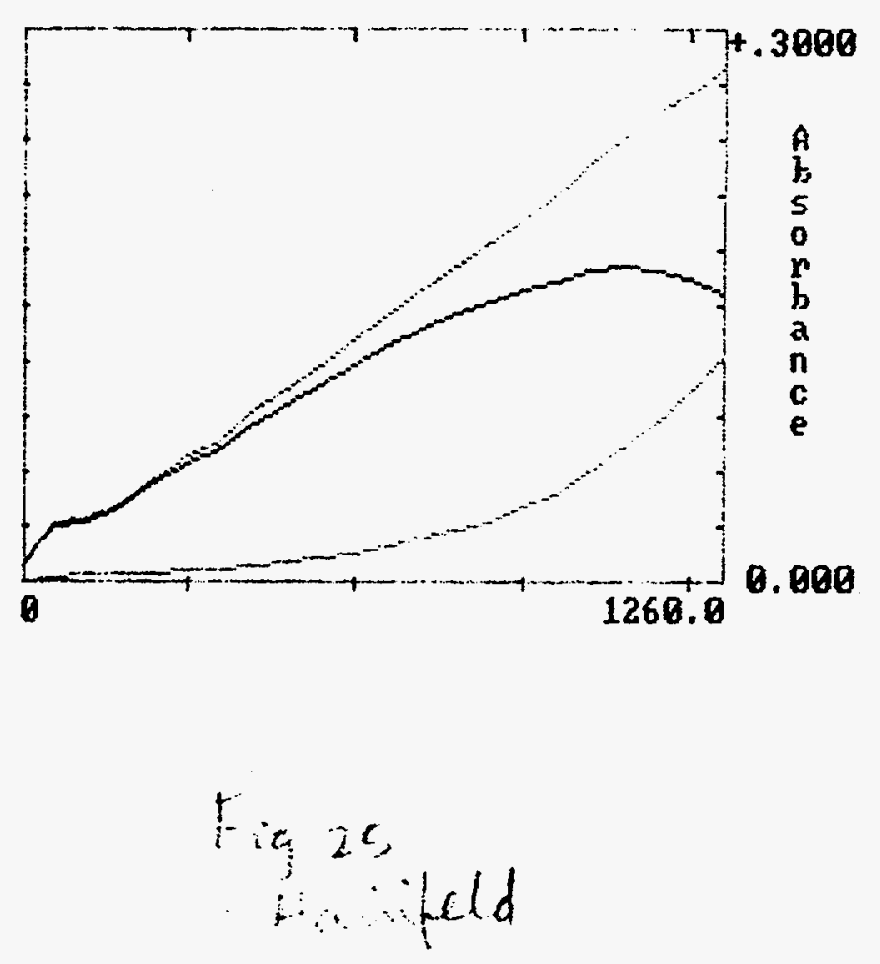




$$
26
$$




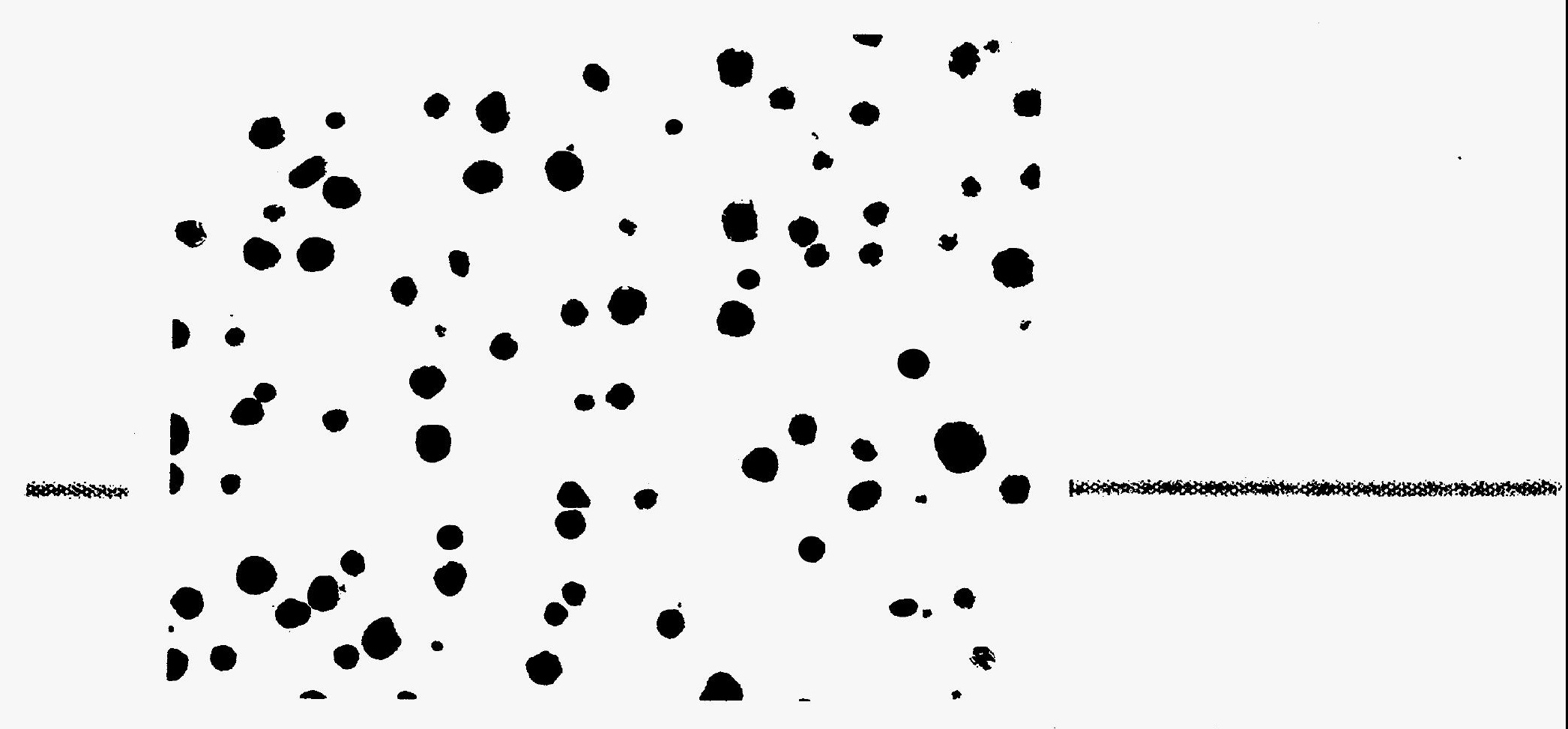

27 


$$
28
$$


29 


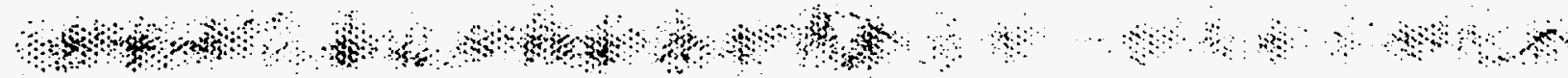

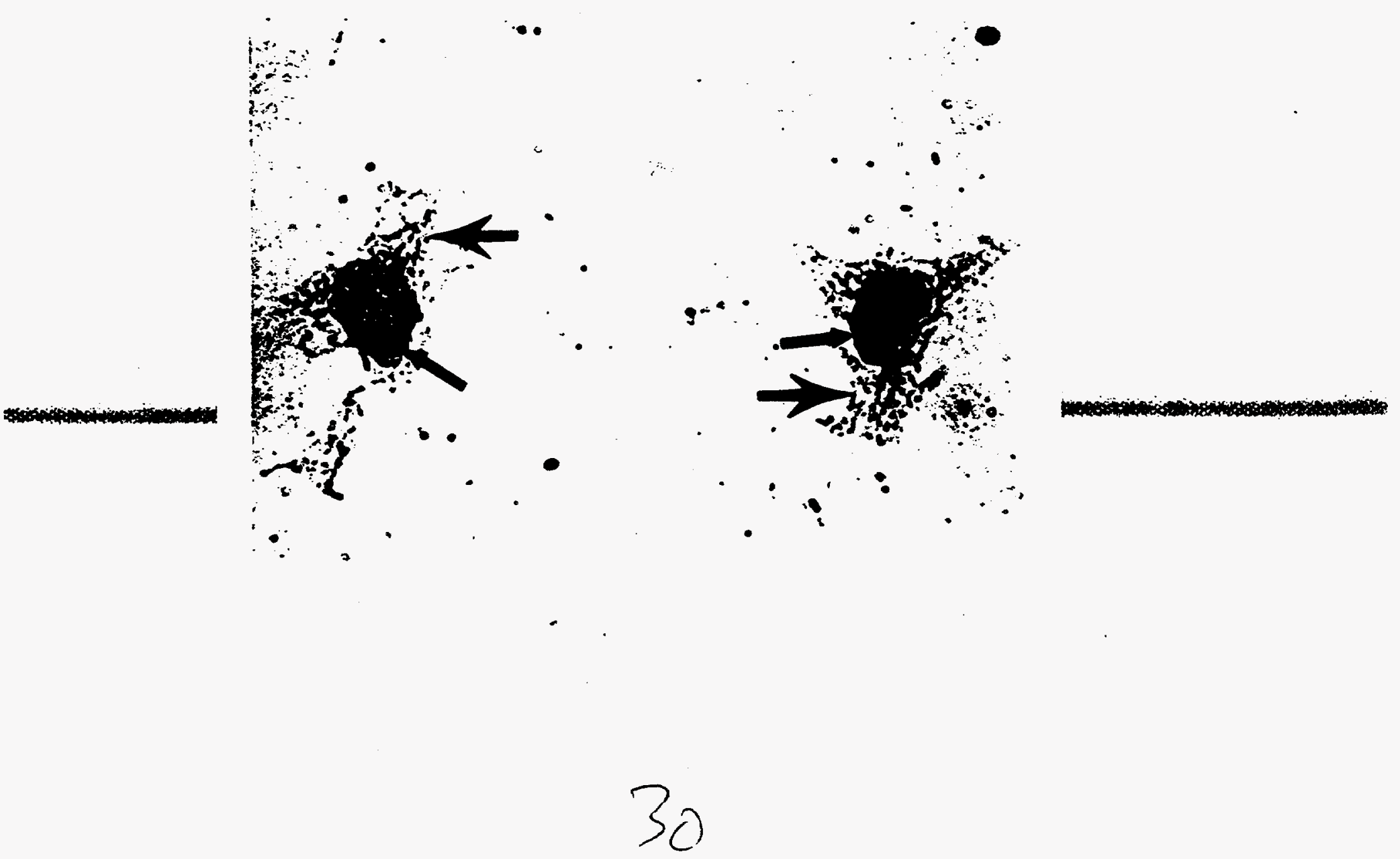




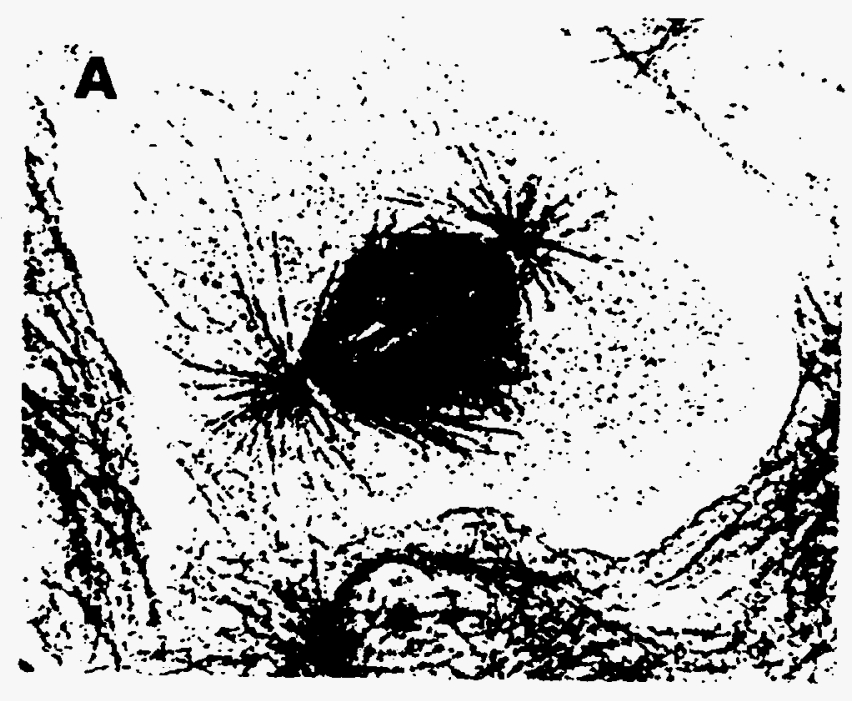

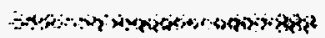

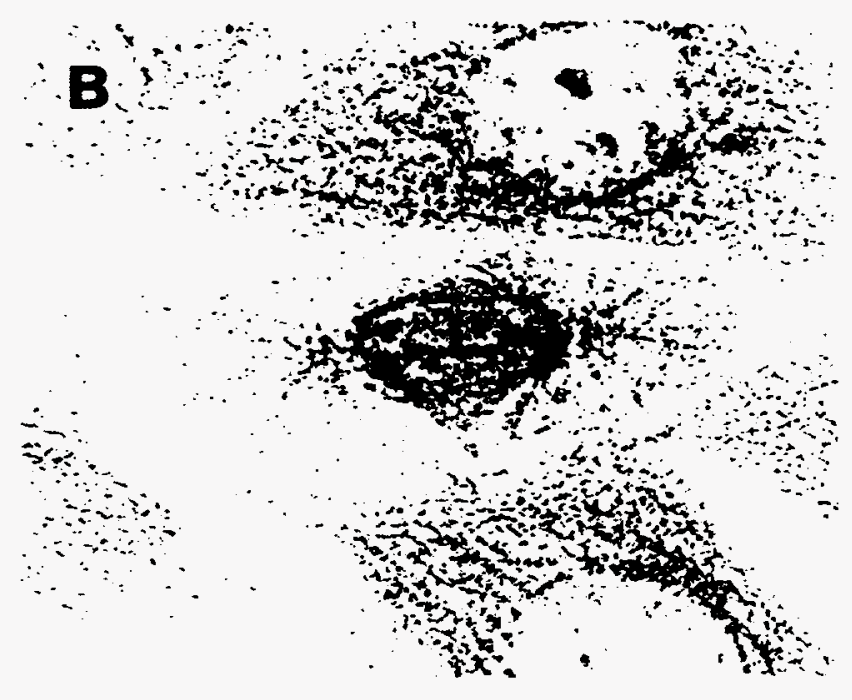

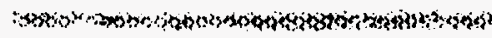




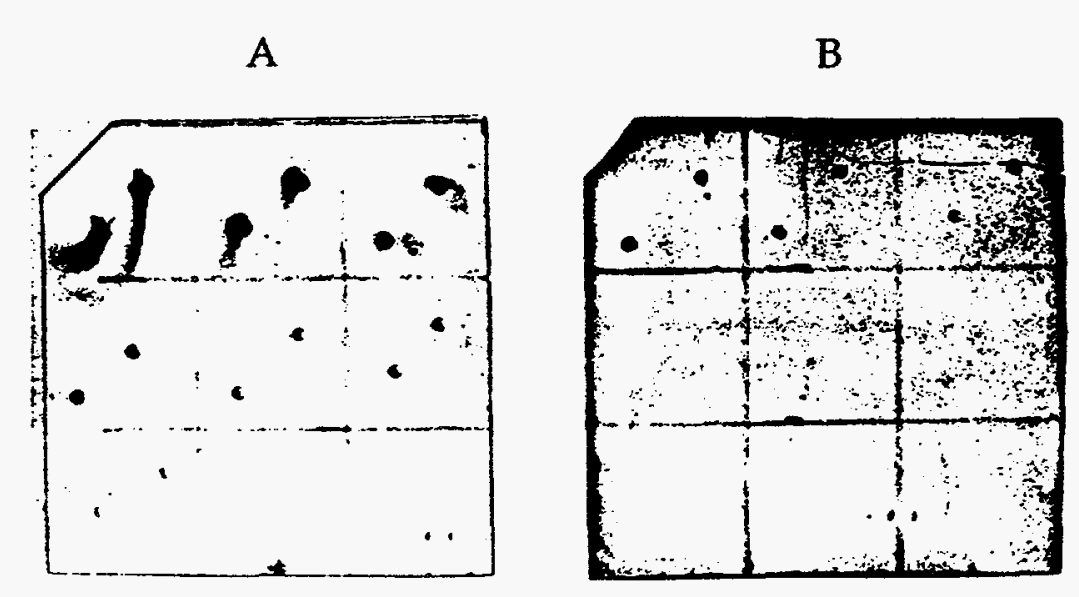

632 


$$
\mathrm{E}
$$




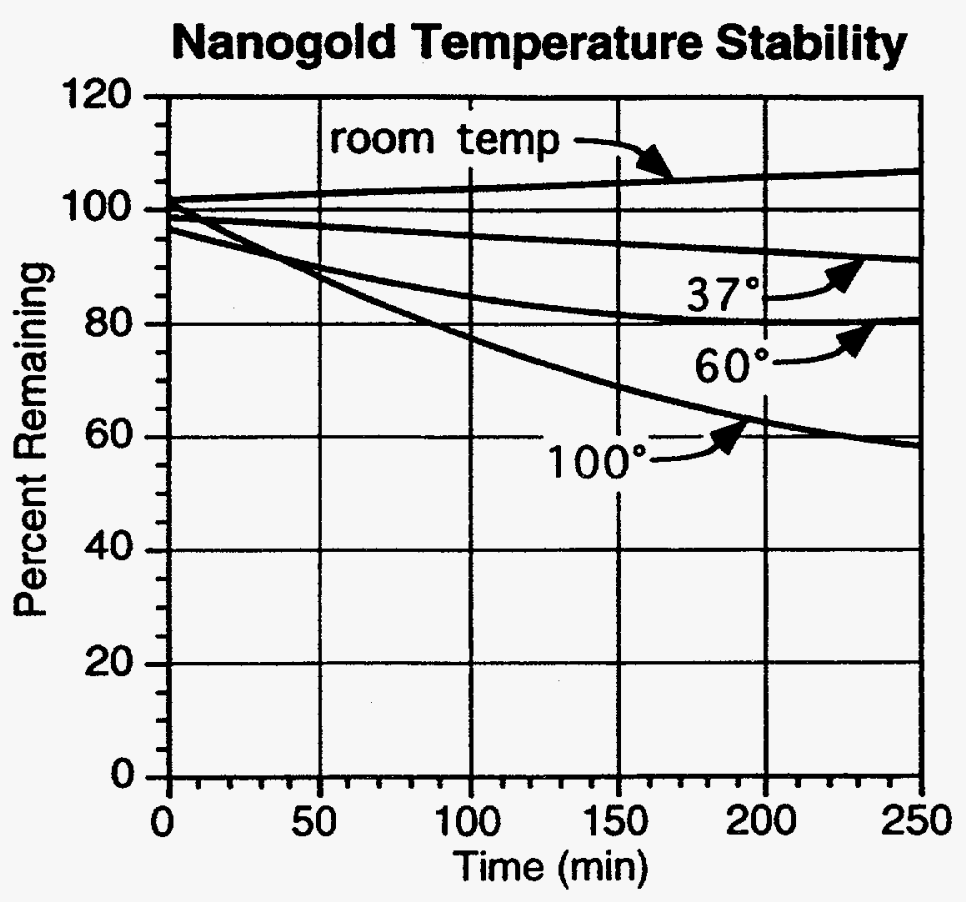

235 


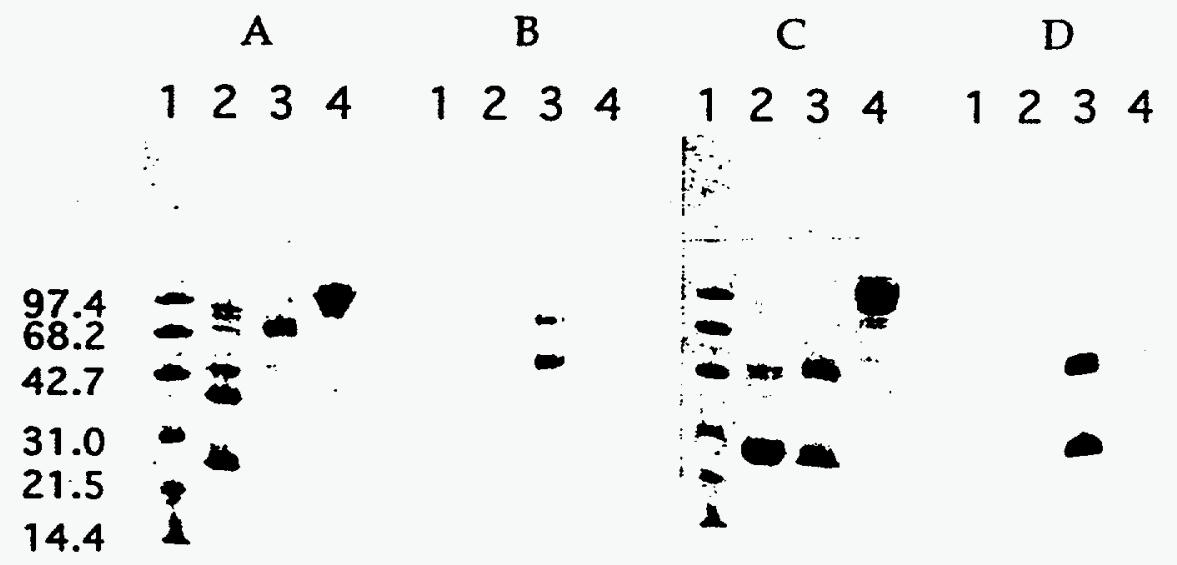

136 